\title{
Companion guide to the marsquake catalog from InSight, Sols 0-478: Data content and non-seismic events
}

Savas Ceylan $^{\mathrm{a}, *}$, John F. Clinton ${ }^{\mathrm{b}}$, Domenico Giardini ${ }^{\mathrm{a}}$, Maren Böse ${ }^{\mathrm{a}, \mathrm{b}}$, Constantinos Charalambous ${ }^{\mathrm{c}}$, Martin van Driel ${ }^{\mathrm{a}}$, Anna Horleston ${ }^{\mathrm{d}}$, Taichi Kawamura ${ }^{\mathrm{e}}$, Amir Khan ${ }^{\mathrm{a}, \mathrm{f}}$, Guenolé Orhand-Mainsant ${ }^{\mathrm{g}}$, John-Robert Scholz ${ }^{\mathrm{h}}$, Simon C. Stähler ${ }^{\mathrm{a}}$, Fabian Euchner ${ }^{\mathrm{a}}$, William B. Banerdt ${ }^{\mathrm{i}}$, Philippe Lognonné, ${ }^{\mathrm{e}}$, Don Banfield ${ }^{\mathrm{k}}$, Eric Beucler ${ }^{1}$, Raphaël F. Garcia ${ }^{g}$, Sharon Kedar ${ }^{i}$, Mark P. Panningi, William T. Pike ${ }^{c}$, Suzanne E. Smrekar ${ }^{i}$, Aymeric Spiga $^{\mathrm{j}, \mathrm{m}}$, Nikolaj L. Dahmen ${ }^{\mathrm{a}}$, Kenneth Hurst ${ }^{\mathrm{i}}$, Alexander E. Stott ${ }^{\mathrm{c}, 1}$, Ralph D. Lorenz ${ }^{\mathrm{n}}$, Martin Schimmel $^{\circ}$, Eléonore Stutzmann ${ }^{\mathrm{e}}$, Jan ten Pierick ${ }^{\mathrm{a}}$, Vincent Conejero ${ }^{\mathrm{e}}$, Constanza Pardo ${ }^{\mathrm{e}}$, Clément Perrin ${ }^{\mathrm{e}}$

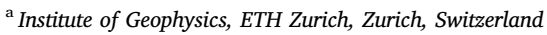

${ }^{\mathrm{b}}$ Swiss Seismological Service, ETH Zurich, Zurich, Switzerland

${ }^{\mathrm{c}}$ Department of Electrical and Electronic Engineering, Imperial College London, London, UK

${ }^{\mathrm{d}}$ School of Earth Sciences, University of Bristol, Bristol, UK

${ }^{\mathrm{e}}$ Université de Paris, Institut de Physique du Globe de Paris, CNRS, Paris, France

${ }^{\mathrm{f}}$ Institute of Theoretical Physics, University of Zurich, Zurich, Switzerland

${ }^{\mathrm{g}}$ Institut Supérieur de l'Aéronautique et de l'Espace SUPAERO, Toulouse, France

${ }^{\mathrm{h}}$ Max Planck Institute for Solar System Research, Göttingen, Germany

${ }^{\mathrm{i}}$ Jet Propulsion Laboratory, California Institute of Technology, Pasadena, CA, USA

${ }^{\mathrm{j}}$ Laboratoire de Météorologie Dynamique, Sorbonne University, Paris, France

${ }^{\mathrm{k}}$ Cornell Center for Astrophysics and Planetary Science, Cornell University, Ithaca, NY, USA

${ }^{1}$ Laboratoire de Planétologie et Géodynamique, Univ. Nantes, Univ. Angers, CNRS, Nantes, France

${ }^{\mathrm{m}}$ Institut Universitaire de France, Paris, France

${ }^{\mathrm{n}}$ Johns Hopkins Applied Physics Laboratory, Laurel, MD, USA

${ }^{\circ}$ Institute of Earth Sciences Jaume Almera of the Spanish Scientific Research Council (ICTJA-CSIC), Barcelona, Spain

\section{A R T I C L E I N F O}

\section{Keywords:}

Mars

InSight mission

Data inventory

Non-seismic signals

Marsquakes

\begin{abstract}
A B S T R A C T
The InSight (Interior Exploration using Seismic Investigations, Geodesy and Heat Transport) mission landed on the surface of Mars on November 26, 2018. One of the scientific instruments in the payload that is essential to the mission is the SEIS package (Seismic Experiment for Interior Structure) which includes a very broadband and a short period seismometer. More than one year since the landing, SEIS continues to be fully operational and has been collecting an exceptional data set which contains not only the signals of seismic origins, but also noise and artifacts induced by the martian environment, the hardware on the ground that includes the seismic sensors, and the programmed operational activities of the lander. Many of these non-seismic signals will be unfamiliar to the scientific community. In addition, many of these signals have signatures that may resemble seismic events either or both in time and frequency domains. Here, we report our observations of common non-seismic signals as seen during the first 478 sols of the SEIS data, i.e. from landing until the end of March 2020. This manuscript is intended to provide a guide to scientists who use the data recorded on SEIS, detailing the general attributes of the most commonly observed non-seismic features. It will help to clarify the characteristics of the seismic dataset for future research, and to avoid misinterpretations when searching for marsquakes.
\end{abstract}

\footnotetext{
* Corresponding author.

E-mail address: savas.ceylan@erdw.ethz.ch (S. Ceylan).

${ }^{1}$ Now at the Institut Supérieur de l'Aéronautique et de l'Espace SUPAERO, Toulouse, France.
} 


\section{Introduction}

InSight launched on May 5, 2018 and successfully landed on Mars on the 26th of November of the same year (Banerdt et al., 2020). SEIS is one of the crucial instrument packages in the payload, consisting of two three-component seismometers (one very broadband or VBB, and one short period or SP), a wind and thermal shield (WTS) to minimize the environmental effects on the seismic sensors, and an electronics box ( $E$ Box) located on the lander for managing sensors and data acquisition (see Appendix A for a list of acronyms). The SEIS and E-box are connected through a tether, the cable used for powering SEIS and transmitting analog signals between the SEIS E-Box and sensor assembly. Detailed information about the seismic instruments and SEIS package is available in Lognonné et al. (2019).

The deployment phase for SEIS started in early December 2018, shortly after the landing, and was completed in February 2019 after the sensors were placed on the planet's surface, the release of the tether and opening of the associated load shunt assembly (LSA), and the placement of the WTS. Fig. 1 shows a sketch of the InSight workspace with various mission components and SEIS sensor orientations. The SEIS package is located approximately to the south of the lander at a distance of $\sim 1.8 \mathrm{~m}$ from the closest lander foot, and $\sim 3.6 \mathrm{~m}$ from the furthest. The $\mathrm{HP}^{3}$ (Heat flow and Physical Properties Package; Spohn et al. (2018)) probe is $\sim 1.2 \mathrm{~m}$ from SEIS.

The primary purpose of the SEIS experiment is to record seismic signals including marsquakes that will provide constraints on the interior structure of Mars. To date, InSight and SEIS have collected an exceptionally valuable and complete data set (InSight Mars SEIS Data Service, 2019a, 2019b). Within the first 478 sols (one sol is $\sim 24 \mathrm{~h} 40 \mathrm{~m}$; we count sols starting from the landing), there were 465 seismic events detected (InSight Marsquake Service, 2020). The first interpretations of the seismicity of Mars and the planet's inner structure are in Giardini et al. (2020) and Lognonné et al. (2020). A complete description of the seismicity catalog, including detection and characteristics of the different suspected seismic signals, is presented in the companion paper by Clinton et al. (2020).

The observation of marsquakes is astonishing by itself, proving that the planet is seismically active. However, events of seismic origins are not the only signals recorded by the InSight seismometers. In fact, the content of the SEIS data is much richer and includes, similar to the Viking seismometer recordings before it (Anderson et al., 1977; Lorenz et al., 2017), other features such as the noise induced by atmospheric conditions, signatures of operational activities performed by the lander's robotic arm, or artifacts caused by the response of the sensors in the severe martian environment. Part of these non-seismic events (i.e. signals not associated with seismic sources such as marsquakes or impacts) have time and spectral domain signatures that resemble seismicity which may lead to misinterpretations, e.g. wind induced signals (Fig. 2). Many of the other observations would be unfamiliar to the scientific community with unusual sources that require clarification,

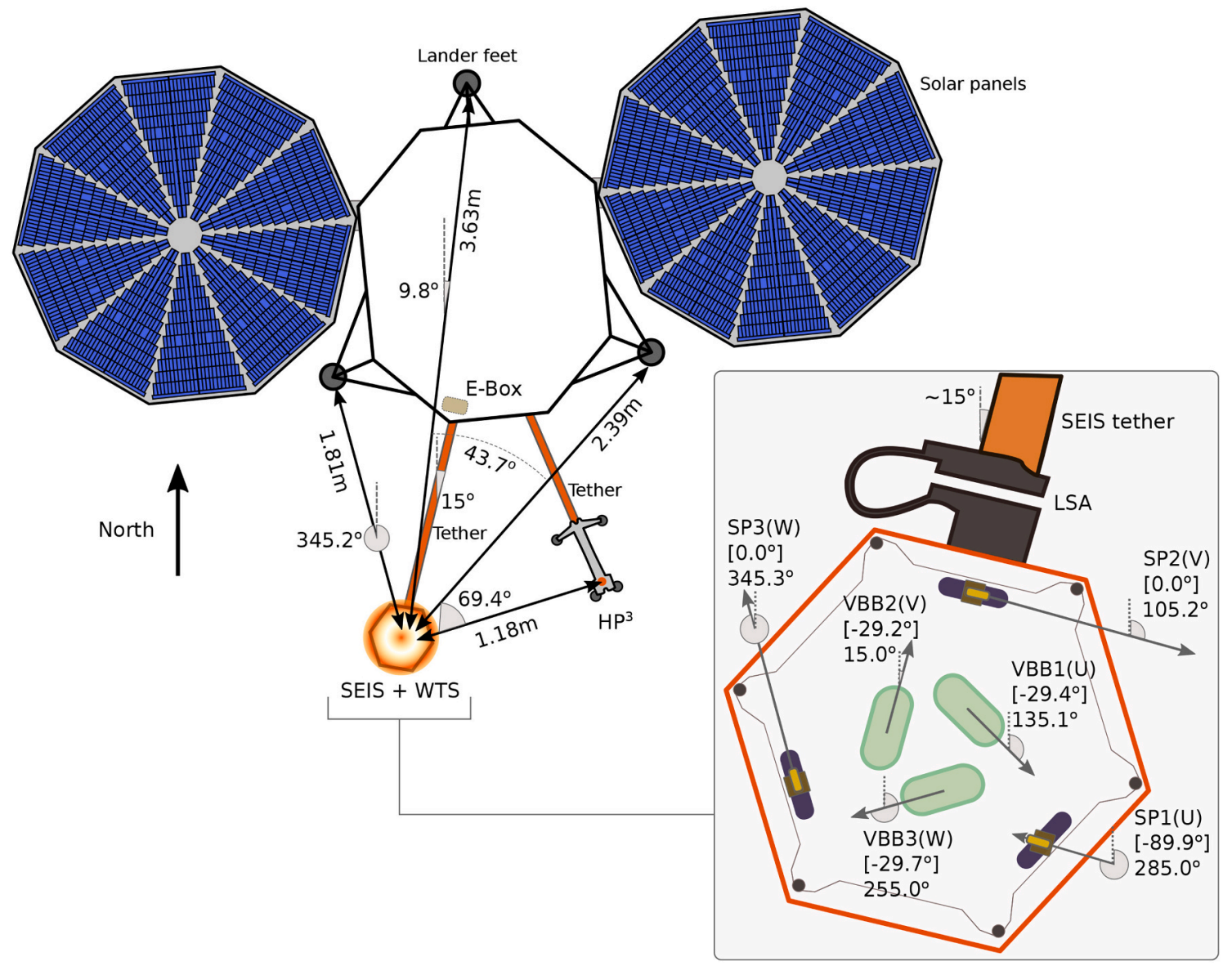

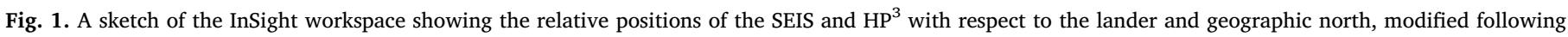

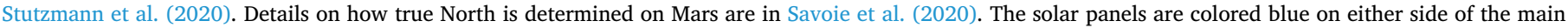

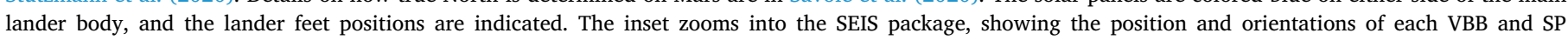

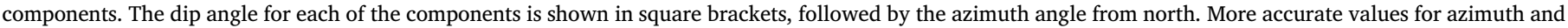

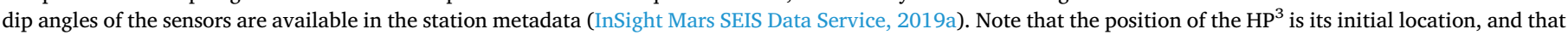

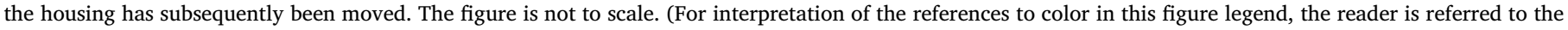
web version of this article.) 


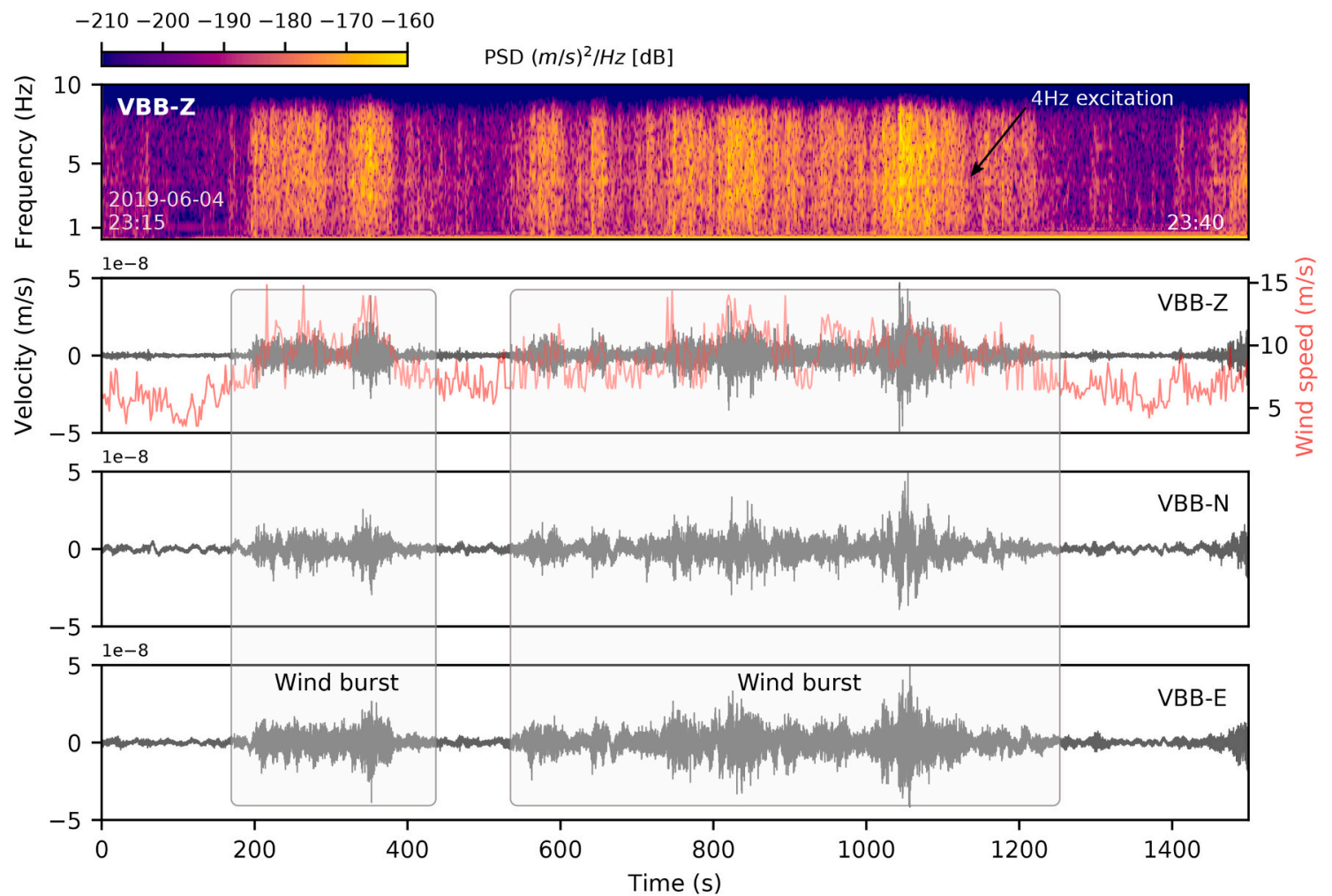

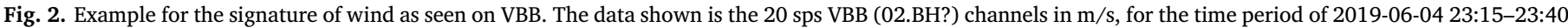

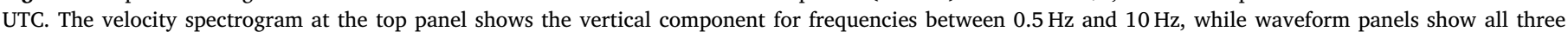

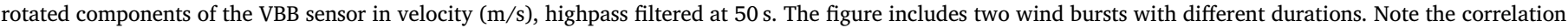
between wind bursts, increase in wind speed (orange line superimposed on the vertical component in the second panel), and the $4 \mathrm{~Hz}$ mode excitation.

e.g. sensors' response to wide range of changes in atmospheric temperature.

Here, we provide a guide for these type of non-seismic events, in order to aid more accurate analysis of the InSight data in future research. We primarily focus on the seismic dataset collected between landing and the end of March 2020 (Sol 478), but we also present data collected from other InSight instruments that may be used for recognizing signals from non-seismic origins. We start with an introduction on the InSight operations, data repository and how non-seismic events are processed. Then, we describe each feature in detail.

The information we give here is complimentary to other studies on the martian background noise and environment. For additional details, we refer readers to Stutzmann et al. (2020) for the polarization analysis of long period ( $>1 \mathrm{~s}$ ) seismic noise of the VBB, Charalambous et al. (2020) for the correlation of noise with wind, and Garcia et al. (2020) and Kenda et al. (2020) for the analysis of noise related to pressure drops and pressure variations. Furthermore, information on an essential component of basic data processing - finding the direction of true North on Mars - is available in Savoie et al. (2020).

\section{Operations and data inventory: a summary}

\subsection{Operations}

The SEIS data (InSight Mars SEIS Data Service, 2019a) from the InSight lander is first transmitted to SISMOC (SEIS on Mars Operations Center). The data is then transmitted to the mission support groups such as the Marsquake Service (MQS), after basic technical processing (e.g. time stamp corrections and file format conversions) in near real time.

MQS is a ground segment support entity within InSight that is responsible for routine data monitoring for detecting seismic signals, locating quakes, and managing the seismicity catalog (Clinton et al.,
2018, 2020). MQS has developed a suite of single-station approaches to determine a distance and back-azimuth (Panning et al., 2015; Khan et al., 2016; Böse et al., 2017), and magnitudes when it is possible to obtain a distance (Böse et al., 2018). The majority of the methods currently employed by the MQS in operations have been vigorously tested prior to landing using synthetic waveforms and event catalogs (Ceylan et al., 2017; Clinton et al., 2017; van Driel et al., 2019).

When a suspected marsquake signal is identified, MQS performs further checks to verify that the signal does not originate from environmental factors. To do this, MQS uses data from the APSS (Auxiliary Payload Sensor Suite; Banfield et al. (2018, 2020)) located on the lander, an additional science package on InSight that includes one pressure sensor, two sensors for measuring wind direction and speed, and a magnetometer (MAG; Johnson et al. (2020)). Along with the APSS data, the activity logs of the lander are also checked to make sure the signal is not caused by known lander activity, for example robotic arm movements or lander communications with the Mars orbiters.

While searching for signals of seismic origin, the MQS team has become familiar with a multitude of non-seismic features and oddities in the waveforms, and at various stages has made efforts to systematically identify these signals. The team manually annotates these observations in order to ensure the completeness of the signal analysis and prevent false event identification. These efforts were most significant at the start of the project, when MQS was unfamiliar with the patterns in the martian dataset.

\subsection{Data inventory}

The data available from InSight (InSight Mars SEIS Data Service, 2019a, 2019b) has varied significantly over the course of the project because of the complexity of InSight operations (in particular during 
Table 1

List of the most common channels MQS has used since landing for identifying and annotating seismic and non-seismic events. $\mathrm{U}, \mathrm{V}$ and $\mathrm{W}$ denotes the three non-orthogonal components of the seismic sensors. 58.BZC is a channel produced on the spacecraft that combines all three components of VBB at 10 samples-per-second (sps) into a single vertical channel; see Lognonné et al. (2019). MAG: the InSight magnetometer, VEL: velocity, SCI: science, ENG: engineering, ERP: event request proposal.

\begin{tabular}{|c|c|c|c|}
\hline Instrument & Loc./Chan. code & Samp. rate (sps) & Description / Comment \\
\hline \multirow[t]{8}{*}{ VBB } & 02.MH [UVW] & 2 & VEL high gain SCI mode \\
\hline & 07.ML [UVW] & 2 & VEL low gain SCI mode \\
\hline & 17.ML [UVW] & 2 & VEL low gain ENG mode \\
\hline & 72.MH [UVW] & 2 & VEL high gain SCI mode \\
\hline & $58 . \mathrm{BZC}$ & 10 & Combined channel VELZ \\
\hline & 03.BH [UVW] & 10 & VEL high gain SCI mode \\
\hline & 02.BH [UVW] & 20 & VEL high gain SCI mode \\
\hline & 00.HH [UVW] & 100 & ERP, high gain SCI mode \\
\hline \multirow[t]{4}{*}{ SP } & 67.MH [UVW] & 2 & High gain \\
\hline & 68.SH [UVW] & 10 & High gain \\
\hline & 67.SH [UVW] & 20 & High gain \\
\hline & 65.EH [UVW] & 100 & ERP, high gain \\
\hline \multirow[t]{4}{*}{ Pressure } & 02.MDO & 2 & \\
\hline & 12.MDO & 2 & Reprocessed on Earth \\
\hline & 03.BDO & 10 & \\
\hline & 13.BDO & 10 & Reprocessed on Earth \\
\hline \multirow[t]{2}{*}{ MAG } & 02.VF [123] & 0.2 & \\
\hline & 02.MF [123] & 2 & \\
\hline
\end{tabular}

the first 70 sols until commissioning was completed), the fluctuating available bandwidth, and demand for data retrieval from all active martian missions. There are major differences in the availability of the various instrumental packages (e.g. SEIS vs. APSS) and instrument types (e.g. VBB vs. SP). Additionally, there are changes in the operational modes of the seismometers (e.g. low vs high gain, and engineering vs science), as well as the sampling rates. InSight adopts an extended version of the SEED (Standard for the Exchange of Earthquake Data) naming conventions (IRIS, 2012), with a unique channel/location code combination for every possible data stream. This leads to a complex inventory of available data, those commonly used are summarized in Table 1 and Supp. Fig. 1. Also, see appendices B and C in Lognonné et al. (2019) for additional details on channel descriptions.

The data volume allocated to InSight for downlink is limited, and varies over time for reasons like orbiter maintenance and requirements of concurrent Mars missions. In the current configuration, InSight continuously transmits $20 \mathrm{sps}$ (samples-per-second) VBB (02.BH [UVW]) and SP (67.SH[UVW]). The configuration for continuous data is updated occasionally to maximize the downlinked data volume that is most useful for science. There are also temporary updates during sensor checkups such as re-centering or calibration, which are activities that are pre-planned and rare. It is possible to retrieve data at higher sampling rates targeting specific scientific goals, e.g. investigating marsquakes in further depth or characterizing a full sol. Although requests for data at higher sampling rates are usually made for $100 \mathrm{sps}$ SP channels (65.EH[UVW]), our data inventory includes limited amount of 100 sps VBB channels (00.HH[UVW]) as well (Supp. Fig. 1).

\section{Overview of non-seismic events and an ordinary sol}

The list of non-seismic events we explore in this paper is provided in Table 2. In an effort to understand and characterise the dataset, the MQS team has been annotating many of these since Sol 70, once the WTS was placed over SEIS and the sensors began collecting high quality data. The procedures to identify all these features summarized in Table 2 varied over the time. For the initial months into the mission, a systematic attempt was made to document all glitches and pressure drops above a certain limit. The procedures were relaxed following conjunction, in part as a response to the increased rate of marsquake observations. From this time, only very large pressure drops were identified, and only glitches associated with seismic signals or suspected seismic signals were annotated.

Fig. 3 presents an overview of the seismic noise for the data collected by the VBB so far, as well as the non-seismic events identified by MQS. See Supp. Fig. 2 for a similar image for the SP sensor starting from Sol 40, which makes apparent both the dramatic reduction in noise following the WTS deployment, and the difference in long period noise resolution between the VBB and SP sensors. The pattern of noise amplitudes changing over the day and across the martian seasons are described in Giardini et al. (2020) and Clinton et al. (2020).

Using polarization analysis, Stutzmann et al. (2020) analyzed continuous data in the frequency band $0.03-1 \mathrm{~Hz}$ and measured both linearly and elliptically polarized signals across the sol. Elliptical signals are dominantly polarized in the vertical plane for frequencies between 0.3 and $1 \mathrm{~Hz}$ and in the horizontal plane for frequencies between 0.03 and $0.3 \mathrm{~Hz}$. Many signals are related to wind and pressure variations and point toward the lander. Charalambous et al. (2020) showed how the identification of atmospheric and other non-seismic source injections can be achieved through comodulation, a spectro-temporal approach describing the correlation in signal power between the environmental variables and ground motion.

The overall pattern of the non-seismic events in Fig. 3 reveal three first order observations: i) There is a strong correlation between the general daily trend of the noise observed by SEIS, the large amplitude glitches and pressure drops. Large glitches are most common between midnight and roughly 07:00 LMST (Local Mean Solar Time). They are no longer identified once the temperature increases with daybreak, when turbulent weather conditions and frequent pressure drops start to dominate the seismic signal. Pressure drops are mainly active between $8 \mathrm{am}$ and $5 \mathrm{pm}$ LMST (Spiga et al., 2020), and stop shortly before sunset, when SEIS records the quietest noise amplitudes. Glitches still occur during the day when winds are strong; however, only the ones with the largest amplitudes can be identified. They are observable again when the calm weather conditions return after the sunset. ii) The largest glitches show a roughly linear trend that follow the seasonal change in temperature. These trends are more clear in the early morning hours before the sunset, and just before the midnight. iii) The evening rumbles start to appear after the solar conjunction and form two distinct clusters in time.

Fig. 4 presents the noise patterns from the VBB vertical component for a typical sol on Mars. The signal is dominated by the noise produced from relatively weak laminar winds that begin in the early morning and last until sunrise, that is followed by stronger, thermally-driven turbulent winds that last throughout the day until nearly sunset (Banfield et al., 2020; Lognonné et al., 2020). The evening period starting from sunset is generally the quietest part of the day.

Several distinct modes are visible as horizontal lines at higher frequencies from $1 \mathrm{~Hz}$ and above, as shown in the acceleration spectrogram in Fig. 4a (also see Table 3 for a summary). These can be separated into 3 main types:

1. Modes at $4 \mathrm{~Hz}$ and above: These modes are thought to be natural frequencies of the lander or the tether system. Energy reaches SEIS via coupling between the lander and ground (Murdoch et al., 2017, 2018), or directly through the tether (Hurst et al., 2020). The strength of these modes positively correlate with the intensity of winds, i.e. they are excited when the lander and solar panels are shaken. The peak frequency and polarization of these modes exhibit a daily pattern that correlates with temperature changes. Charalambous et al. (2020) identified that modes below $<10 \mathrm{~Hz}$, including the significant modes around $4 \mathrm{~Hz}$ and $7 \mathrm{~Hz}$, become abruptly attenuated below a seasonal-dependent wind-speed threshold close to $2.4 \mathrm{~m} / \mathrm{s}$. Additional modes can be seen at higher frequencies, up to $40 \mathrm{~Hz}$. The energy for each of these excitations is significantly higher on the horizontal components than the vertical, 
Table 2

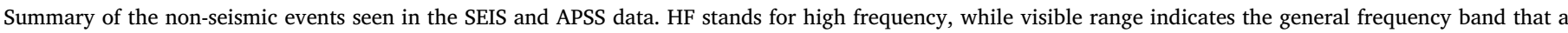

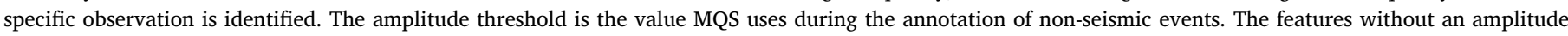

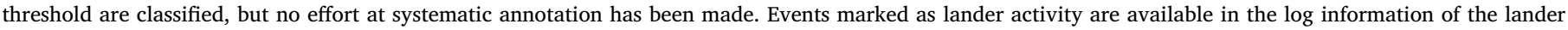
operations.

\begin{tabular}{|c|c|c|c|c|c|}
\hline Event class & Dominant frequency & Instrument & Amplitude threshold & Duration & Remarks \\
\hline Donks & $\geq 10 \mathrm{~Hz}$ & VBB, SP & $10^{-6} \mathrm{~m} / \mathrm{s}$ & $3-5 \mathrm{~s}$. & very frequent \\
\hline Glitches & broadband & VBB, SP & $10^{-7} \mathrm{~m} / \mathrm{s}$ & $30-35 \mathrm{~s}$. & very frequent \\
\hline Temperature pattern & long period & SP & - & sol long & one per sol; repeats daily \\
\hline Pressure drops & broadband & VBB, Pressure & $0.1 \mathrm{~Pa}, 1.0 \mathrm{~Pa}$ & - & several per sol \\
\hline Evening rumbles & long period & VBB, Pressure & no threshold & $1-3 \mathrm{~h}$ & one per sol; not daily \\
\hline Crosstalk & $>1 \mathrm{~Hz}$ & $\mathrm{SP}, \mathrm{VBB}$ & - & sol long & repeats daily \\
\hline VBB1 whistling & $<1 \mathrm{~Hz}$ & VBB [U] & - & - & repeats daily \\
\hline Sunset chirps & $\leq 0.5 \mathrm{~Hz}$ & VBB [East] & - & - & not daily, few a sol \\
\hline Sandmen & $\sim 5-7 \mathrm{~Hz}$ & SP [V] & not annotated & - & not daily, one per sol \\
\hline \multicolumn{6}{|l|}{ Other common signals } \\
\hline Arm motion & $\geq 4 \mathrm{~Hz}$ & VBB, SP & lander activity & - & \\
\hline Calibration & broadband & VBB, SP & lander activity & - & \\
\hline Heater activation & broadband & VBB, SP & lander activity & - & \\
\hline
\end{tabular}

and the modes are generally quite narrow band, indicative of modal vibrations with low damping.

2. $2.4 \mathrm{~Hz}$ resonance: The $2.4 \mathrm{~Hz}$ mode is a natural ambient resonance that appears to originate from the substructure beneath the lander (Giardini et al., 2020). In contrast to the modes from the spacecraft system, it is vertically polarized with strongest amplitude on the vertical component, and does not fluctuate in frequency or amplitude following changes in the temperature or local wind intensity. This resonance is significantly broader than the other modes. It is not visible during periods with heavy winds as the weak amplitude is obscured in the noise. Its amplitude and azimuth (angle from the North in horizontal plane) do vary during the day with highest amplitude in the late evening, and subtle changes in overall amplitude do occur over the seasons. It is the only mode that is systematically excited by seismic waves and amplifies seismic signals above the noise (van Driel et al., 2020).

3. $1 \mathrm{~Hz}$ mode: This signal is also referred to as the tick-noise. It is an artifact produced by crosstalk from temperature analogue signals of the $E$-Box measurement system. The E-Box works with $1 \mathrm{~s}$ cycles to the science and house-keeping signals, which are acquired by its data acquisition system. It also performs temperature measurements on the sensors at a sample rate of 1 sps. For these measurements, which consist of sending a current through a thermistor, both the current source and the acquisition circuitry are shared. One set of these exists for the temperatures measured by the housekeeping system, and another set for the VBB temperatures. Therefore, switching is performed to send the current through each of the thermistors within the $1 \mathrm{~s}$ cycle, to obtain a value for each of the temperatures. The currents are sent over the tether, which also carries the science signals to the E-Box. The crosstalk between the signals on the tether, and possibly within the sensor assembly, cause the $1 \mathrm{~s}$ period tick-noise on both sensors, more dominantly on the VBB components.

The amplitude of the crosstalk signal is sub-LSB (Least Significant Bit), and only becomes apparent in the frequency spectrum when long durations of data are analyzed. LSB is the physical value for one count of the digital number. The E-Box can digitize a 24-bit number for a full range of $\pm 25 \mathrm{~V}$ for VBB, so the value of the LSB is $50 \mathrm{~V} /$ $2^{24}=\sim 30 \mu V$. Both the amplitude and frequency of the tick noise are constant throughout the day. Higher harmonics may also be seen, for instance at $2 \mathrm{~Hz}$ and $4 \mathrm{~Hz}$.

The excitation of the $2.4 \mathrm{~Hz}$ and lander modes serve as a discriminant to identify if a signal is from a seismic origin or not, i.e. seismic events do not excite the lander modes, while wind does not excite the $2.4 \mathrm{~Hz}$ mode (Giardini et al., 2020). For future reference, we emphasize that when a suspicious signal is detected on SEIS recordings, it should also be checked against the common patterns we describe here, as well as the APSS channels and lander activity.

Although we generally use the lander modes (e.g. Figs. 4 and 8) to discriminate between weather induced phenomena and seismic events, there are often cases for which the $2.4 \mathrm{~Hz}$ excitation coincides with the lander modes' excitation (Clinton et al., 2020), which is not surprising considering the prevalence of wind-associated signals in the dataset. The current MQS seismicity catalog does include many examples of seismic events with high frequency energy that occur during the quiet period of the sol and do not excite the lander modes. The opposite case is also very common where we observe long period wind energy exciting the lander modes but not the $2.4 \mathrm{~Hz}$ resonance. The co-excitation of both the natural and lander modes is relatively rare.

The lander modes and their variable characteristics is not new for extraterrestrial missions. For instance, Latham et al. (1971) reported that lander noise was an unexpectedly problematic feature of the first extraterrestrial seismology observations, the Apollo 11 Passive Seismology Experiment, even though the instrument was placed some $16.8 \mathrm{~m}$ from the nearest leg of the Lunar Module (LM). Subsequent Apollo experiments had the seismometers deployed about $100 \mathrm{~m}$ from the LM, but even then, lander noise was apparent, especially during the long lunar dawn and dusk. A lander resonance of $7.2 \mathrm{~Hz}$ was seen when the astronauts were on the surface, which shifted to $8.0 \mathrm{~Hz}$ when they departed. Specifically to InSight, Panning et al. (2020) present the data from the SP sensor while on-deck and show these lander modes occur with significantly higher amplitudes.

Note that the change in the rate of occurrence of non-seismic events after solar conjunction in Fig. 3b is a result of an update in MQS's strategy when annotating these features: Single and multi-component pulses (referred to here as glitches in general), donks, and pressure drops are very frequent. Therefore, MQS annotates these observations when they are above an amplitude threshold. All glitches with a minimum amplitude of $10^{-7} \mathrm{~m} / \mathrm{s}$ and pressure drops of $0.1 \mathrm{~Pa}$ were picked until Sol 265. After Sol 265, MQS started annotating the most apparent glitches only around potential seismic signals without a certain threshold, and pressure drops at or above $1 \mathrm{~Pa}$ (Table 2). This update on MQS procedures was in response to a marked increase in the observation of marsquakes in the months preceding conjunction (Clinton et al., 2020).

\section{Non-seismic event descriptions}

SEIS data includes broad patterns that are ideally observed on a 


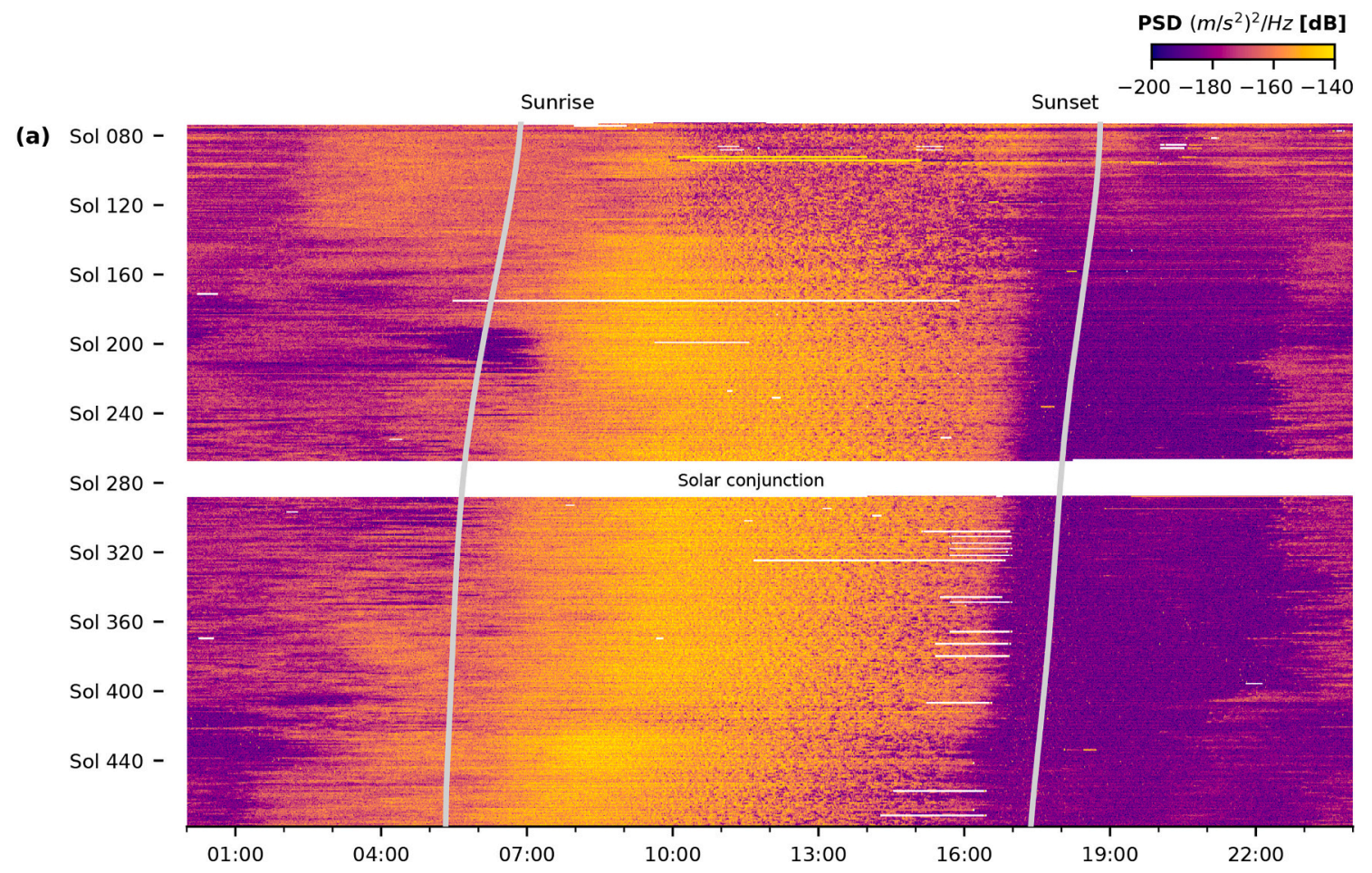

(b)

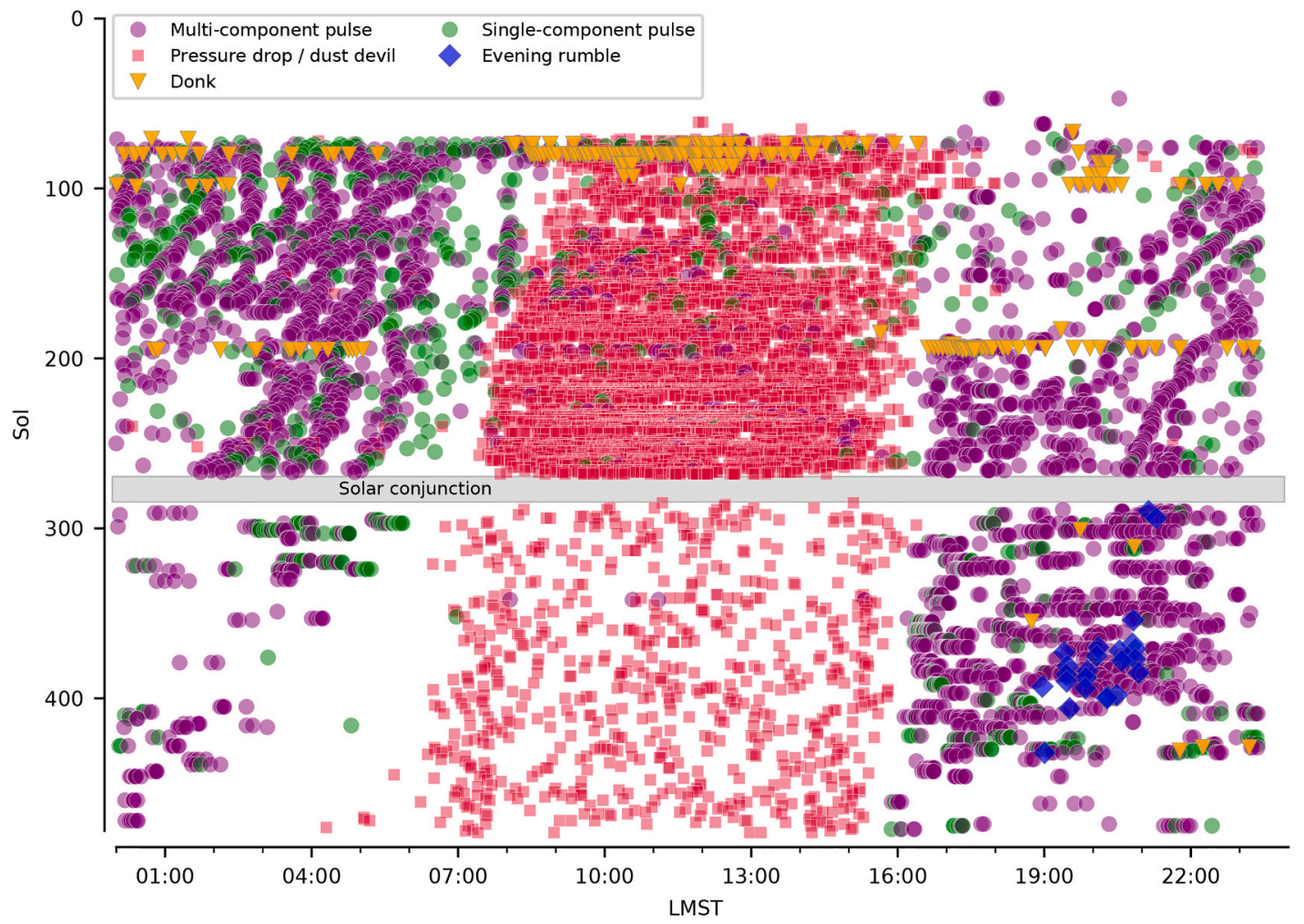

Fig. 3. Evolution of seismic noise as seen on VBB between sols 76-478 (a) and the non-seismic events included in the MQS database (b). Each horizontal strip in (a) shows the acceleration spectrogram for one sol from $4 \mathrm{~Hz}$ to $25 \mathrm{~s}$. Data used in (a) is a combination of VBB vertical, 58.BZC, or VBB1. Glitches are shown as either single or multi-component pulses in (b). No data was retrieved during the solar conjunction. The MQS procedures for annotating key non-seismic events were updated following the conjunction.

whole sol scale or relatively longer time windows at the order of several hours, i.e. the response of the SP sensor to temperature change, crossfrequency modes on both VBB and SP, and evening rumbles. Other features listed in Table 2 occur at much smaller scales with distinct spectral or time domain signatures.

\subsection{Donks}

Donks are short duration pulses of high frequency energy that are typically observed on all three components of both seismometers simultaneously at frequencies higher than $\sim 12 \mathrm{~Hz}$ (Fig. 5). Due to their 


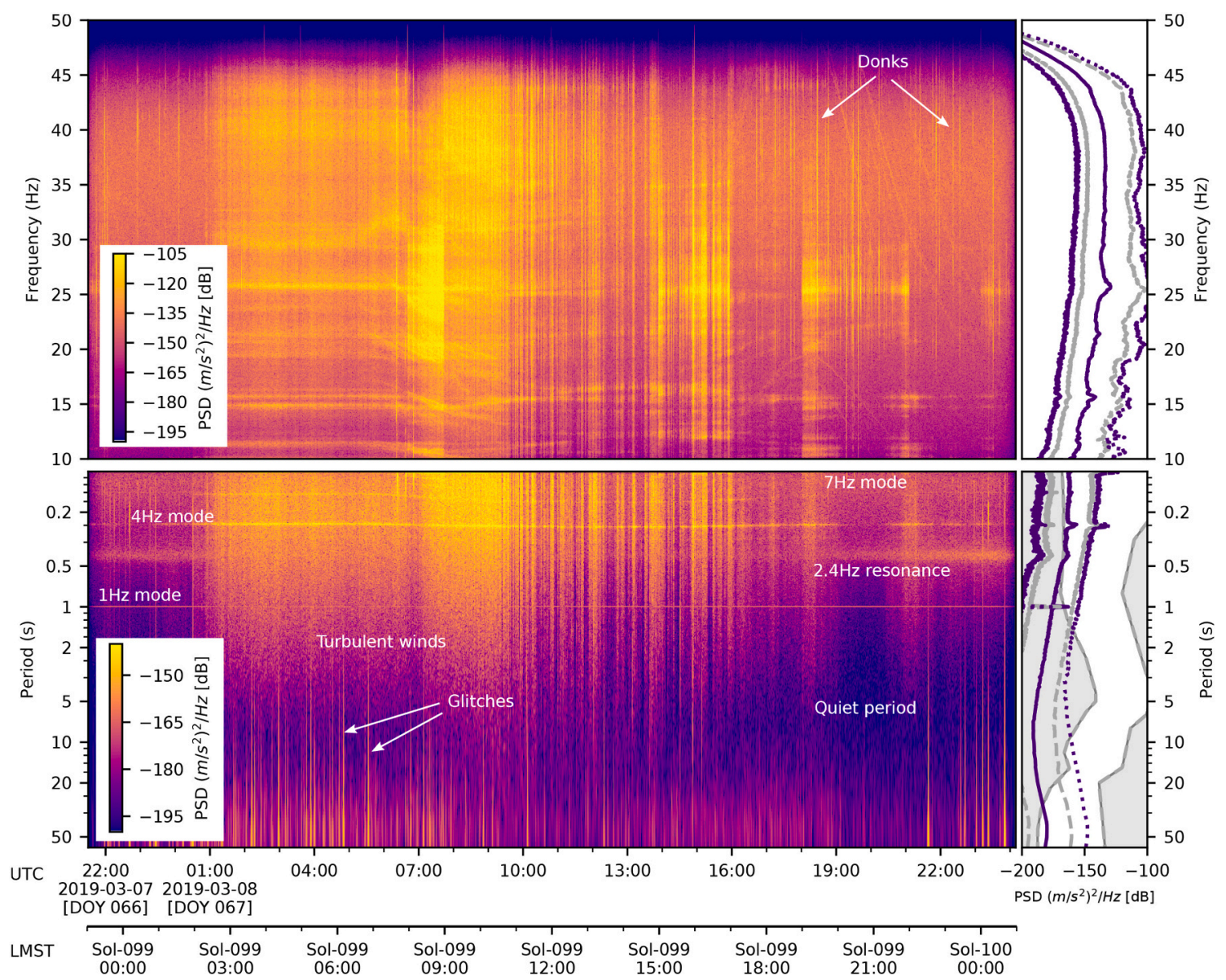

Fig. 4. An example sol on Mars (Sol 99), showing acceleration spectrograms for 100 sps VBB (00.HH?) vertical component and average power spectral density (PSD). (a) for frequencies $10-50 \mathrm{~Hz}$ in linear scale, and (b) for longer periods between 0.1 and $50 \mathrm{~s}$ in log scale. The solid lines in the side panels are median PSDs, with dotted lines indicating percentiles of 1\%, 5\%, 90\%, and 95\%. For comparison, the shaded areas in the PSD panels indicate regions outside the Earth high and low noise model. Note that Sol 99 was early on in the mission, and the noise regime is substantially different to subsequent days (Fig. 3a), when marsquakes became routinely identified - it was selected as it is a rare occasion with 100 sps VBB data available. Common spectral modes and some non-seismic events are marked.

higher frequency content, they are only clearly visible on the 100 sps VBB and SP channels, which are downlinked on demand for specific science or engineering purposes. Donks occasionally may have tails injecting energy at frequencies lower than $8 \mathrm{~Hz}$. They are visible on 20 sps channels when the tail of energy is lower than $10 \mathrm{~Hz}$, but their signature on the waveforms is vague.

The typical duration of donks is at the order of a few seconds, with a waveform pattern that may resemble micro quakes. Donks at different times of the day can have very different waveform and spectral signatures. They typically start with an impulsive energy that then excites numerous lander modes. They are a prevalent feature in high sample rate data, with many hundreds occurring each day. MQS has not attempted to annotate all examples. On rare occasions for a short period, donks with amplitudes $\geq 10^{-6} \mathrm{~m} / \mathrm{s}$ have been annotated.

Donks are thought to be transient energy associated with stress release from temperature cycling on the lander, tether, or SEIS. This is

Table 3

Overview of predominant modes and resonances observed in the SEIS data.

\begin{tabular}{|c|c|c|}
\hline Mode/resonance & Source & Common characteristics \\
\hline $1 \mathrm{~Hz}$ & E-Box (known) & Very narrow resonance peak. No temperature dependency. Shows harmonics at $2 \mathrm{~Hz}, 3 \mathrm{~Hz}$ etc. \\
\hline $2.4 \mathrm{~Hz}$ & $\begin{array}{l}\text { shallow structural resonance below SEIS } \\
\text { (presumed) }\end{array}$ & $\begin{array}{l}\text { Broad natural resonance that may be overlapping with other modes at close frequencies at } 2.3 \mathrm{~Hz} \text { and } 2.6 \mathrm{~Hz} \text {. Its } \\
\text { amplitude and orientation varies during the day. Excited by seismic signals and also apparently modulated by } \\
\text { regional weather. }\end{array}$ \\
\hline $4-\sim 10 \mathrm{~Hz}$ & Lander & $\begin{array}{l}\text { Shift in frequency during the day time with the temperature variations corresponding to higher amplitudes when } \\
\text { wind is also stronger. Also excited in the quiet periods; well correlated with the wind intensity. Rarely excited by } \\
\text { donks. }\end{array}$ \\
\hline $12-40 \mathrm{~Hz}$ & Lander and WTS & $\begin{array}{l}\text { Varying temperature dependency. Strongly excited by donks. Splitting signals during the day, indicating crosstalk } \\
\text { overlaps. }\end{array}$ \\
\hline
\end{tabular}



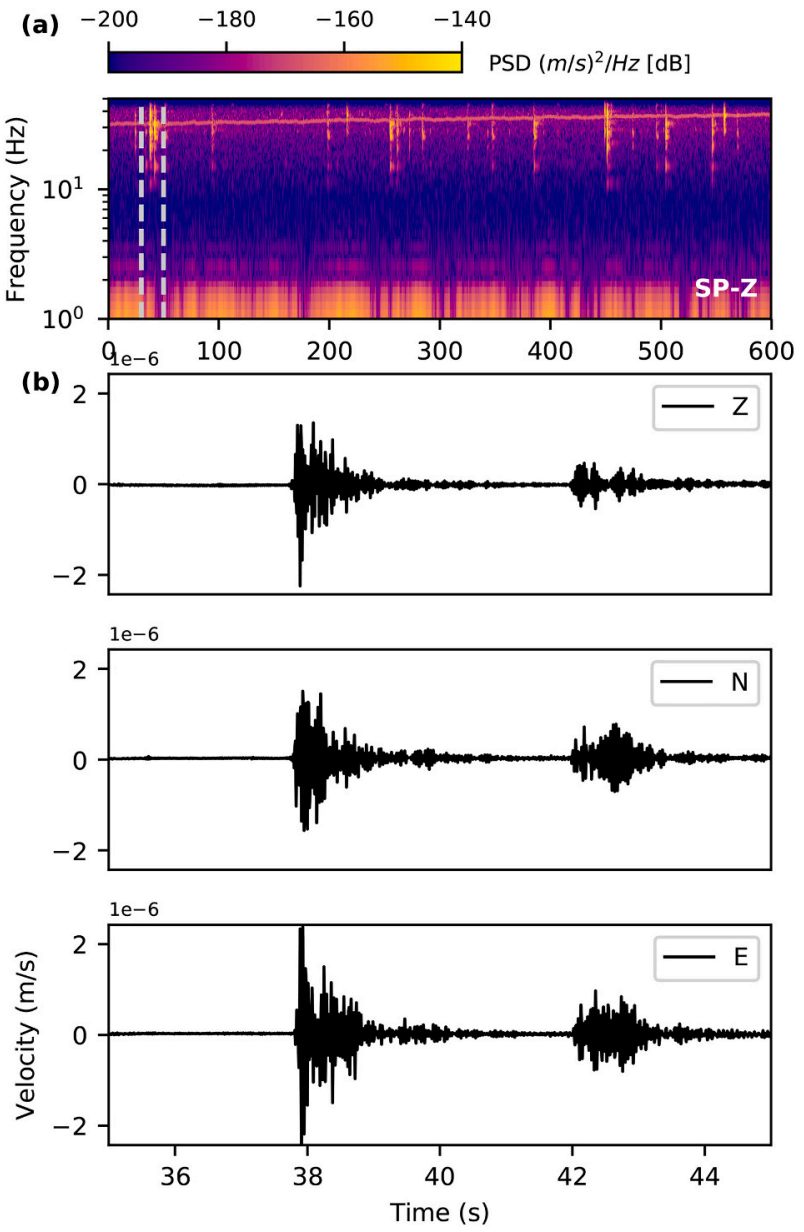

Fig. 5. Donk examples as seen on the $100 \mathrm{sps}$ SP data (channel 65.EH?). (a) Velocity spectrogram for the vertical component, and (b) three component waveform plots for the time frame marked with vertical dashed lines in (a). The time scale in (b) is only $10 \mathrm{~s}$ long starting from 2019-07-30 13:36:00 UTC (Sol 239 18:13:42 LMST). Note that donks can be ubiquitous in the data, and have significant variation in amplitude, as well as seismic signal shape and spectral content.

corroborated since donks excite frequencies associated with lander modes also excited by winds in contrast to the glitches (see the next section).

Donks are most visible at different periods of the day, in particular during mornings and evenings outside of the heavy winds, which may obscure their observation. Unfortunately, this is the same period during which the majority of marsquakes are observed at lower frequencies. Hence, it is normal to observe these signals overlain on the seismic signal. Fortunately, it is rare for marsquake signals to have frequency content overlapping donks. A special type of seismic signal that is archived by MQS, labeled as super high frequency (shortly SF) events, does have a similar duration as donks, but differs as the energy is broadband throughout its excitation, not just exciting lander modes. See Clinton et al. (2020) and Dahmen et al. (2020) for further discussion and examples of both donks and SF events.

\subsection{Glitches}

Glitches are by far the most frequent type of anomaly observed on the 20 sps VBB channels. The SP waveforms also contain some glitches that often can be linked to the sensor response to daily temperature changes.

The waveform of glitches (Fig. 6) can be understood and modelled as the instrument response convolved with a step in the recorded acceleration. Glitches therefore manifest in the time domain raw data as one-sided pulses with a duration of $\sim 25-30 \mathrm{~s}$ independent of their amplitudes, and in the spectral domain as very broadband energy blocks reaching from lowest frequencies up to $1 \mathrm{~Hz}$ and higher for the strongest glitches. Glitches may occur on only one single component as well as on all three components; some glitches even occur simultaneously on all six seismic components (VBB and SP together). There are numerous glitches that include superimposed high frequency ringing at the beginning. For these high frequency glitches, the ringing is referred to as a spike and usually coincides with a donk that reaches below $5 \mathrm{~Hz}$.

As is the case for most of the non-seismic events we outline in this paper, the detailed mechanisms that cause glitches are still under debate. Many glitches are associated to the release of thermal stresses at the individual sensor level or within the SEIS main frame. Other glitches that are occurring on multiple components can be explained by the SEIS assembly tilting in the order of nano-radians, causing a different projection of the gravity vector on the individual components (a step in acceleration). For these cases, glitch spikes are thought to represent the instrument response of a step in displacement associated to such tilt of the SEIS assembly.

We also observe glitches correlating well with the activity time stamps of InSight's robotic arm, indicating that certain lander activities cause impulsive ground tilts. However, arm motions are rare so this is an exceptional explanation.

Finally, we observe a subset of glitches that occur predominantly on the north component with positive polarity after sunset and with negative polarity during the day. In our current understanding, these glitches could be related to tilts induced by the tether and/or load shunt assembly under the changing wind and temperature regime. Overall, considering the temporal variability of glitches with very different character, it is likely there are multiple different sources for glitches.

Similar to the donks, some glitches are linked to the release of thermal stresses in the SEIS main frame. A comprehensive analysis of glitches recorded by both VBB and SP can be found in Scholz et al. (2020) as well as the supplement 5 of Lognonné et al. (2020). Since a number of VBB glitches have an onset that is coincident with donks, it is likely both features sometimes originate from a common source. However, both donks and glitches are very recurrent signals; hence, some level of correlation would be expected.

Glitches are artifacts that contaminate the data with their impulsive, broadband characteristics that span a wide range of amplitudes. Many standard seismological methods (e.g. receiver functions, spectral decomposition, noise analysis) are sensitive to the presence of glitches and care must be taken. Hence, glitches should be avoided where possible or attempted to be removed (Scholz et al., 2020).

Until Sol 265, the MQS annotation database includes all glitches with amplitudes larger than $10^{-7} \mathrm{~m} / \mathrm{s}$ as well as all visible glitches during any identified marsquake. After this, only visible glitches around the seismic events are included.

\subsection{SP temperature pattern}

The SP sensor has a well established and predictable response to the temperature variations throughout the sol (see Fig. 7 for an example from Sol 204) and so exhibits a repeating pattern of high amplitude spikes and long period drift. The VBB sensor is also affected by thermal 

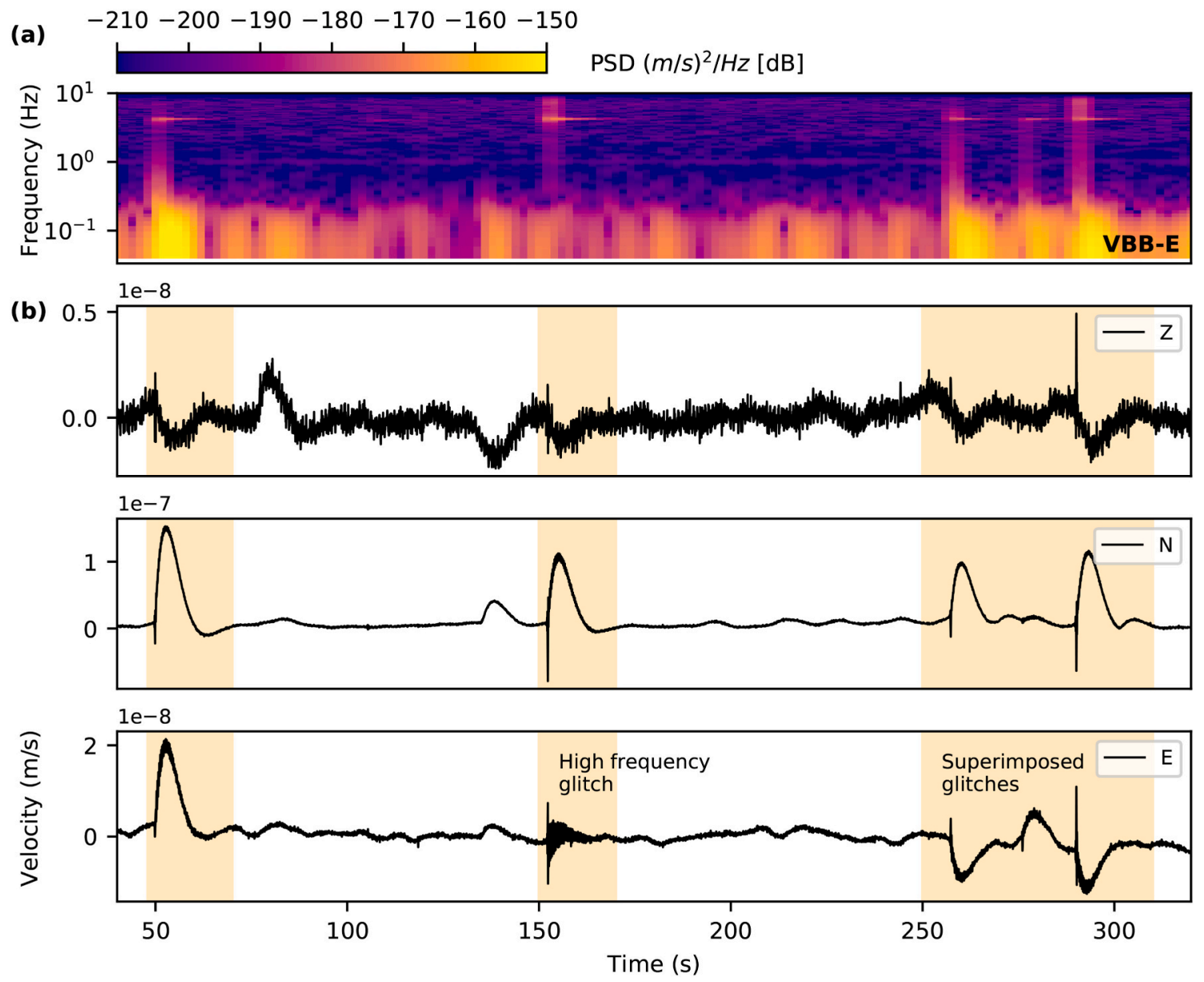

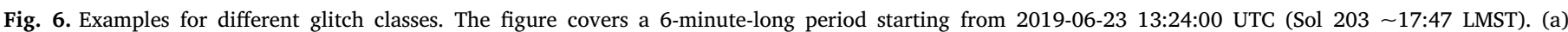

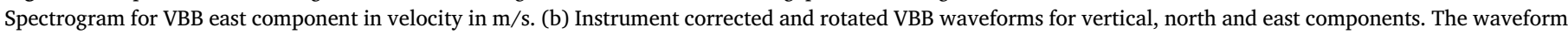

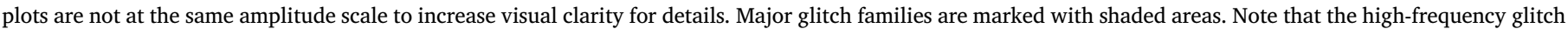
is preceded by another glitch with a relatively smaller long period amplitude.

changes as seen in the full sol waveforms, though not as severely. The SP velocity output is proportional to jolt (the derivative of acceleration) at longer periods, whereas its response to temperature is in acceleration. The sensor's thermal response consists of both a linear and thermoelastic component (Stott et al., 2018). The SP1 (or U, the vertical component) has a predominantly linear response in acceleration, and is the most sensitive to temperature. The horizontal sensors SP2 (V) and SP3 (W) naturally have a lower sensitivity, in fact, SP3 (W) is observed to have very little. The SP2 (V) sensor's velocity channel though has a slightly larger sensitivity and includes sudden steps (Fig. 7b,c), which correspond to a step change in the sensitivity itself, noting that these steps are in jerk.

For the example sol shown, there are temperature induced glitches on SP2 (always positive direction) and SP3 (always negative direction) at the beginning of the SP pattern's first stage, as well as on all VBB components (Fig. $7 \mathrm{~b}$ ), occurring at around $-48^{\circ} \mathrm{C}$. SP1 has one positive and one negative glitch each end of the temperature cycle when the sensor die reaches $-48^{\circ} \mathrm{C}$.

These patterns have changed over the course of the mission, depending on the temperature profile. A particularly marked change occurs on Sol 168 where the SEIS heaters were turned on. This moved the regular glitches observed on the horizontal SP sensors (SP2 and SP3) from $-56^{\circ} \mathrm{C}$ to $-47^{\circ} \mathrm{C}$.

\subsection{Crosstalks and whistling}

Both the VBB and SP sensors exhibit transient signals with frequencies that steadily migrate higher or lower over timescales on the order of hours - which could also be described as wandering signals or crosstalk. These are most visible in the 100 sps data as the signals are more pronounced above $10 \mathrm{~Hz}$.

The frequency of these signals correspond exactly to the velocity counts from each channel (low-pass filtered $<2 \mathrm{~Hz}$ ) and are an artifact that appears to be created by internal crosstalk in each channel, either in the tether cabling or electronics, which injects an amplitude to frequency modulation from the input to the output in a process which is not fully understood. Hence these crosstalk signals are scaled versions of the raw velocity counts seen in Fig. 7, with the SP sensor repeating well-established patterns observed at frequencies $>1 \mathrm{~Hz}$ (Fig. 8a) repeated over many sols.

As crosstalk injects on to each SP and VBB sensor, if the sensor outputs are mixed to produce the horizontal SP and all three VBB 


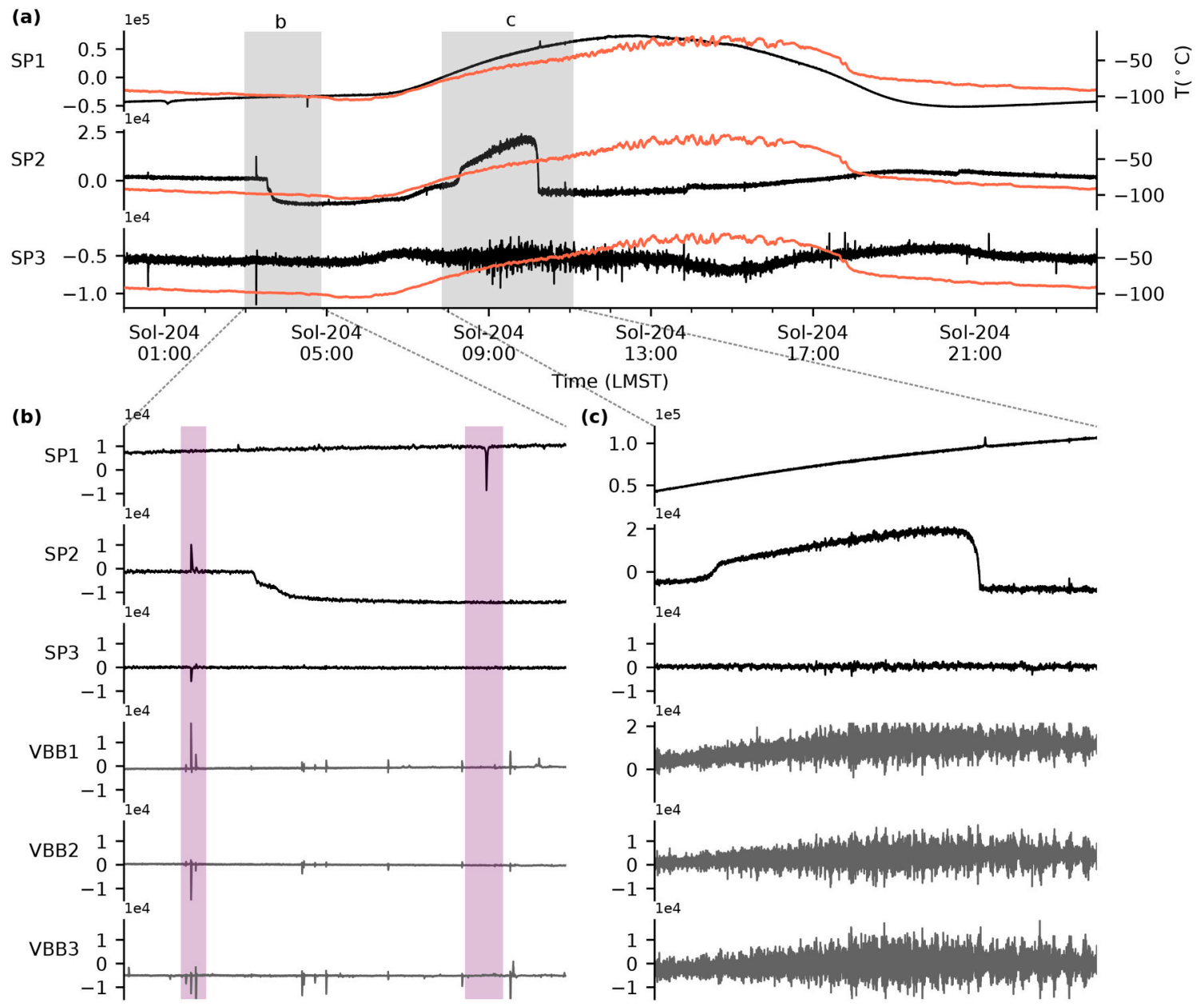

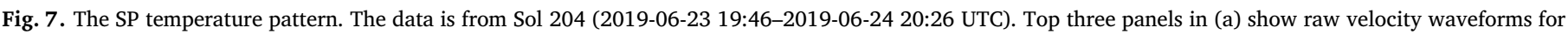

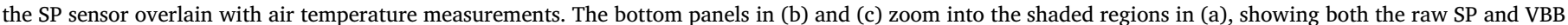

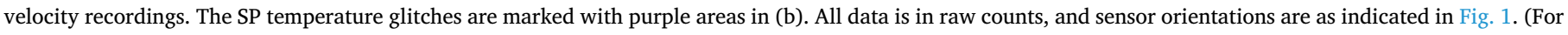
interpretation of the references to color in this figure legend, the reader is referred to the web version of this article.)

components, the crosstalk appears as a superposition, with a more complex form (Fig. 8b). At lower frequencies, the crosstalk injection moves quickly across the bandwidth, and is generally less apparent though if the counts are changing more slowly it can be identified.

Another type of transient signal observed on SEIS data is called as the whistling. The main distinction between whistling and crosstalk is that whistling is seen only on one sensor without any crosstalk between instruments or sensors. An example for VBB is shown in Fig. 8c, labeled as VBB1 whistling in Table 3. Fig. 10b demonstrates another example or migrating spectral signals seen on the SP2 sensor that we term sandman, which is explained together with the sunset chirps in a separate section below due to their similarities in spectral shape and time of occurrence.

\subsection{Atmospheric effects: wind, pressure drops, evening rumbles}

Although the noise was dramatically reduced by the deployment of WTS, the sensors remain far from fully isolated from the martian environment. SEIS is very sensitive to atmospheric conditions, particularly to the wind effects (Fig. 2). The wind effects are observed in the seismic records as very broadband and frequent features that could be confused with seismic signals in the time domain, specifically throughout the mid-day when weather conditions are rather more turbulent (Fig. 2). Additional modes excited by the lander-wind interaction (e.g. at $4 \mathrm{~Hz}$ and $7 \mathrm{~Hz}$ ) are very strong during the same time period. The temperature dependency of the lander modes is clearly visible on spectrograms with excitation frequencies lower than the quieter periods (Fig. 4 and 8a,b).

There are two primary atmosphere related events we describe in further detail here:

1. Pressure drops (Fig. 9a): MQS is systematically annotating transient drops in the pressure channel as pressure drop/dust devil (see Fig. 3b). They have a clear broadband signature on the seismic data. These are vortices in the martian atmosphere, which may or may not be visibly dust-laden. The low-pressure vortex system applies a negative load to the ground, causing a measurable tilt away from the vortex (Lorenz et al., 2015), from which the ground compliance can be derived (Lognonné et al., 2020; Banerdt et al., 2020; Kenda et al., 2020). They are daily evident in the seismic recordings depending on their intensity and proximity to SEIS. Pressure drops are very common during the early afternoon turbulent periods when 

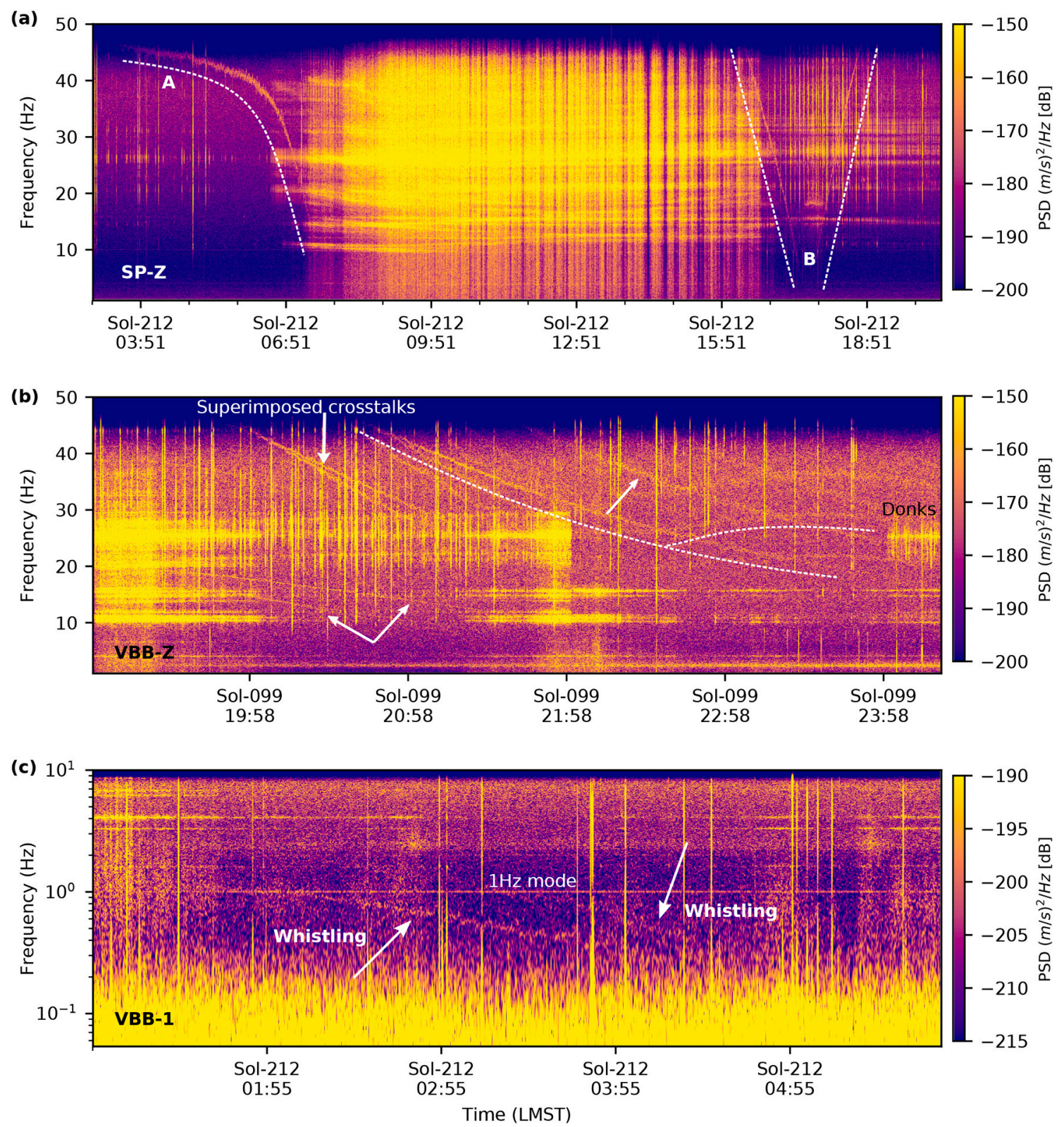

Fig. 8. Crosstalk and whistling signals as seen in the velocity spectrograms for SP and VBB from sols 99 and 212. The instrument and component names are shown in the lower-left corner of each panel. The frequency axis scale is linear in (a) and (b), and logarithmic in (c). In (a), we show the two distinct SP crosstalk patterns from the 100 sps data (A and B; also outlined with dashed lines) that are visible before and after the windy period. Panel (b) shows different crosstalk examples from VBB 100 sps data at frequencies $>1 \mathrm{~Hz}$. In (c) we show an example of whistling on the VBB1 below $1 \mathrm{~Hz}$, marked with arrows.

temperature is higher (Spiga et al., 2020). An investigation that used SEIS records of pressure drops to identify observed satellite images of dust devil tracks is included in Banerdt et al. (2020). Fluctuations of pressure outside the daytime hours are related to gravity waves and bores (Banfield et al., 2020) and develops over longer periods than daytime vortex-induced pressure drops.

2. Evening rumbles: Evening rumbles are relatively long period $(>\sim 2 s)$, pressure induced signals on SEIS with a duration of $2-3 \mathrm{~h}$. Their signatures on the seismic time series are not very distinct, and their spectral signature resembles what are known as low frequency
(LF) events in the Marsquake catalog (Clinton et al., 2020) - though they have significantly longer duration and longer period excitation. They are visible during the quiet periods in the evening, associated with the long period change in atmospheric pressure (Fig. 9b). Evening rumbles may also appear like wind gusts; however, it is straightforward to distinguish them as the lander modes are not excited during the rumbles. For the strongest events of this type, a clear correlation can be seen between the vertical component VBB and the pressure sensor. For weaker examples, the pressure signal cannot be seen above the noise and the classification is purely based 


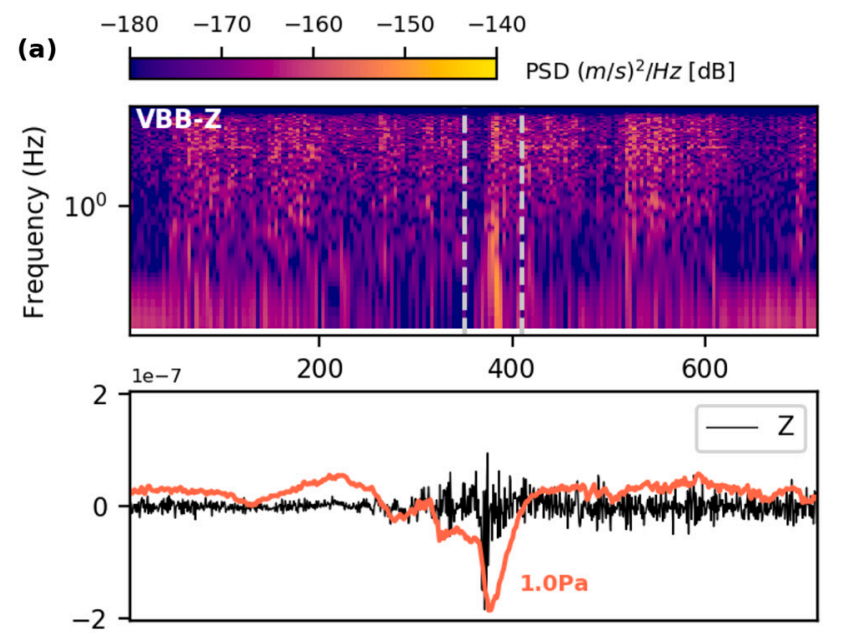

(b)
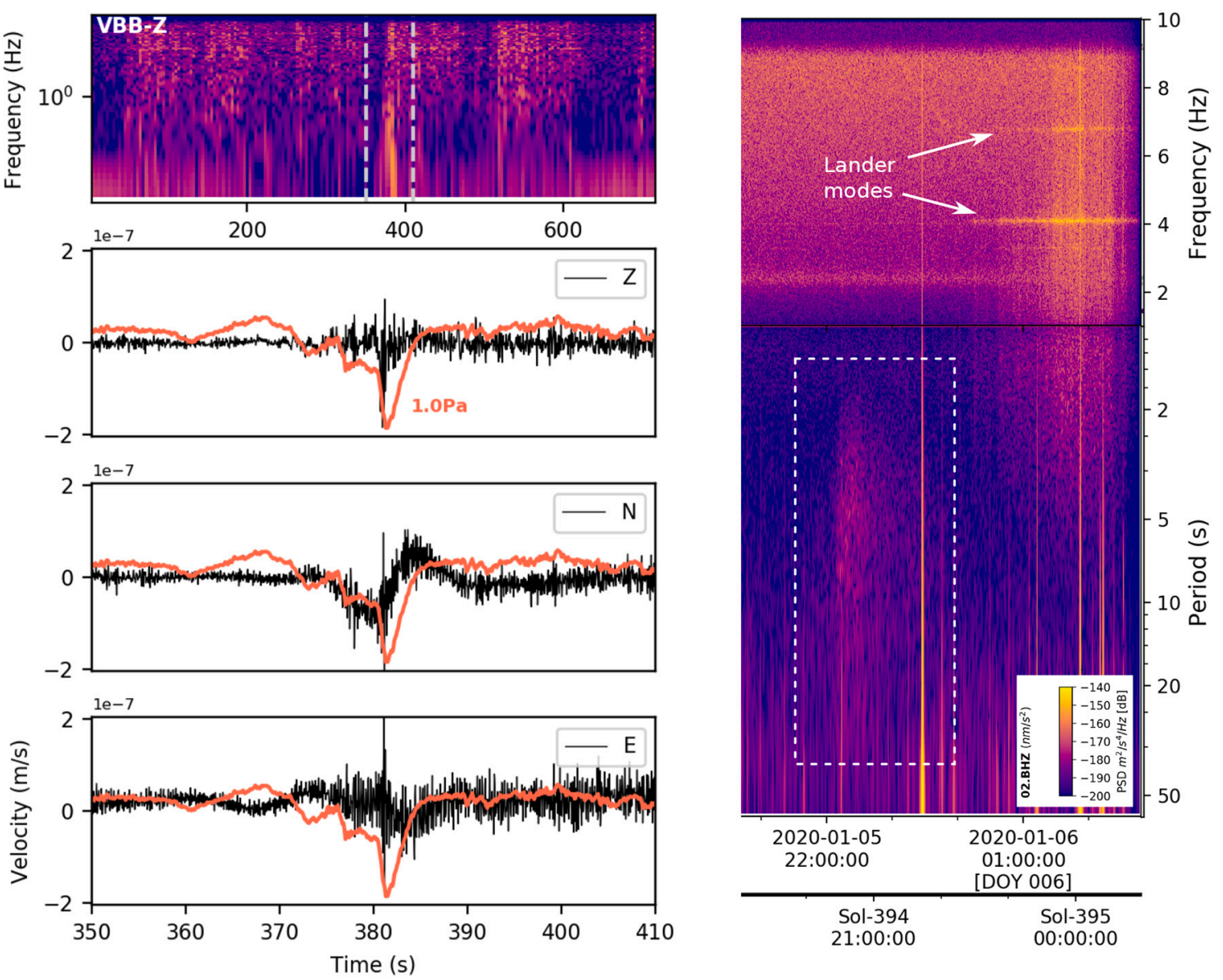

Fig. 9. Examples for (a) pressure drop, and (b) evening rumble. The seismic data used in (a) is gain-removed 20 sps VBB velocity in $\mathrm{m} / \mathrm{s}$. The pressure drop shown in the figure (orange lines) has an amplitude of $\sim 1 \mathrm{~Pa}$. Seismic components are indicated in the waveform panels. The spectrogram belongs to VBB vertical components. Panel (b) shows acceleration spectrogram for vertical component of VBB with two lander modes (arrows) and evening rumble marked (rectangle).

on the seismic data. Evening rumbles started to appear after the solar conjunction period. They are most probably seasonal features. Readers are referred to Garcia et al. (2020) for more information on the correlation the VBB and pressure.

\subsection{Sunset chirps, sandmen}

Sunset chirps are another example of frequency domain features that occur in the evening hours after the windy period (Fig. 10a). They usually last for $\sim 30-60 \mathrm{~min}$, with no apparent time-domain signature. They are most commonly observed on the east component of the VBB, at periods $\sim 4-35 \mathrm{~s}$.

Sunset chirps are characterised by a fishbone-like pattern on the spectrograms. They have energy packages that look dispersive with several overtones, increasing in frequency over time. The pattern is mirrored with similar modes that are decreasing in amplitude, and finally vanishing.

Similar to VBB's sunset chirps, a frequent spectral-domain feature occurs on the SP2 during the quiet hours, which we term sandman
(Fig. 10b). A sandman has an inverted V-shaped pattern with no extra apparent modes. It persistently appears for a two-hour-long period between 18:00-20:00 LMST, with a relatively weak energy in the 5-8 Hz band. This feature might be seen with slightly different patterns, for instance circular rather than V-shaped, or only parts of the pattern visible.

Note that the sandman is essentially a whistling, as it is a crossfrequency phenomenon that is only observed on the SP2, and there is no indication of a similar pattern on other sensors. We list this feature here with the VBB sunset chirps due to their similarities in spectral shape and time of occurrence.

\subsection{Other common signals}

Other signals that regularly appear in the SEIS data are those generated by the lander activities or sensor maintenance operations. It is generally clear that such events are artificial; however, without easy access to the lander information, it can easily to be confused by these signals when analysing an unfamiliar dataset from another planet. 

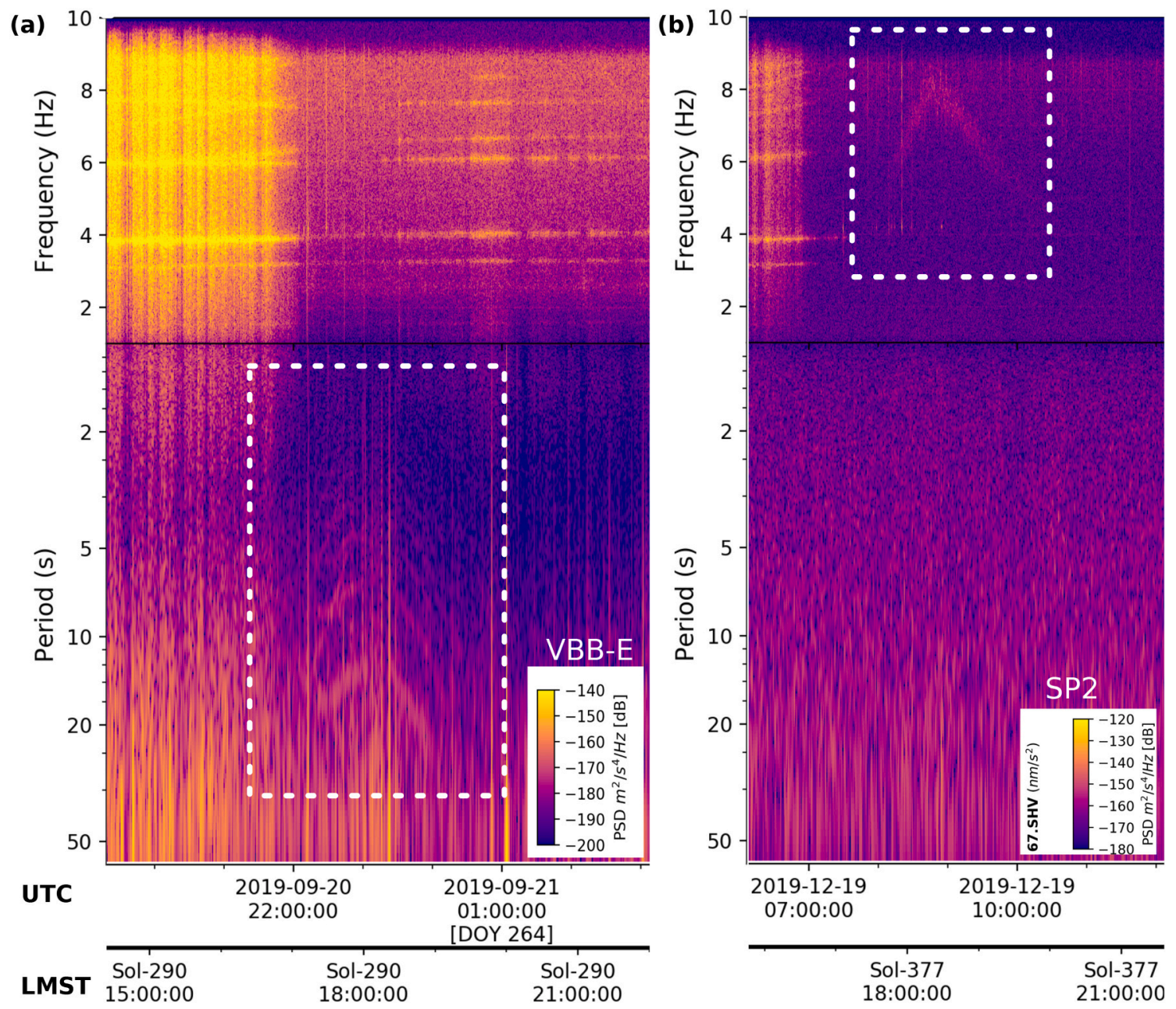

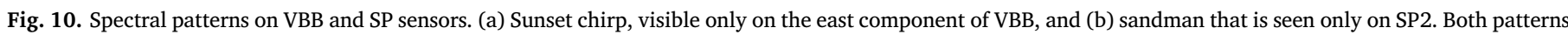
are marked with the white dashed rectangles.

Therefore, we briefly give three examples for these type of signals including signatures of InSight's robotic arm, VBB calibration, and SEIS heater (Fig. 11).

The InSight lander has a robotic arm with a camera mounted on it. The arm has been actively used for deployment, other activities that require interaction with the instruments on the ground, and imaging the surroundings. It has been used significantly beyond the original plan in the efforts to help the $\mathrm{HP}^{3}$ mole as it struggles to bury itself under the Martian surface. An arm motion is typically characterised on SEIS by a series of relatively high frequency $(>4 \mathrm{~Hz}$ ) and dispersive signals on both VBB and SP (Fig. 11a). The characteristics depend on the performed activity.

The SEIS sensors go through occasional quality control measures similar to a seismic station on Earth, including re-centering and sensor calibration. An example of how calibration looks on SEIS is shown in Fig. 11b. Calibration signals are visible on both sensors and all components.

SEIS has internal heaters in order to maintain the health of electronics and mechanical components. The heaters are activated when inside temperatures for any component threaten to drop below $-65^{\circ} \mathrm{C}$, depending on the configuration of flight software. When the heaters are turned on, they cause impulses on the sensors which are damped over time, resembling a boxcar-shaped response on SEIS (Fig. 11c).

\section{Conclusions}

We presented the general characteristics of commonly observed signals of non-seismic origins in the seismic data of InSight between the landing and Sol 478 (end of March 2020). The SEIS data is dominated by the artifacts from the atmospheric conditions that are more evident during the windy periods, but also may occur in the quiet periods. These artifacts have time and spectral domain properties that may resemble seismic signals. Any automated approach to detect signals of seismic origins may be affected by the signatures of these anomalies, and care must be taken in any analysis. Glitches and donks are particularly ubiquitous features and hence need to be handled with care when interpreting InSight seismic data.

\section{Data availability}

The InSight seismic event catalog version 3 (InSight Marsquake Service, 2020) and waveform data (InSight Mars SEIS Data Service, 2019a) are available from the IPGP Datacenter and IRIS-DMC. Seismic waveforms are also available from NASA PDS (National Aeronautics and Space Administration Planetary Data System; https://pds.nasa. gov/). A sample data set of daily mini-seed files as well as example source codes for plotting, waveform processing, and LMST conversions 

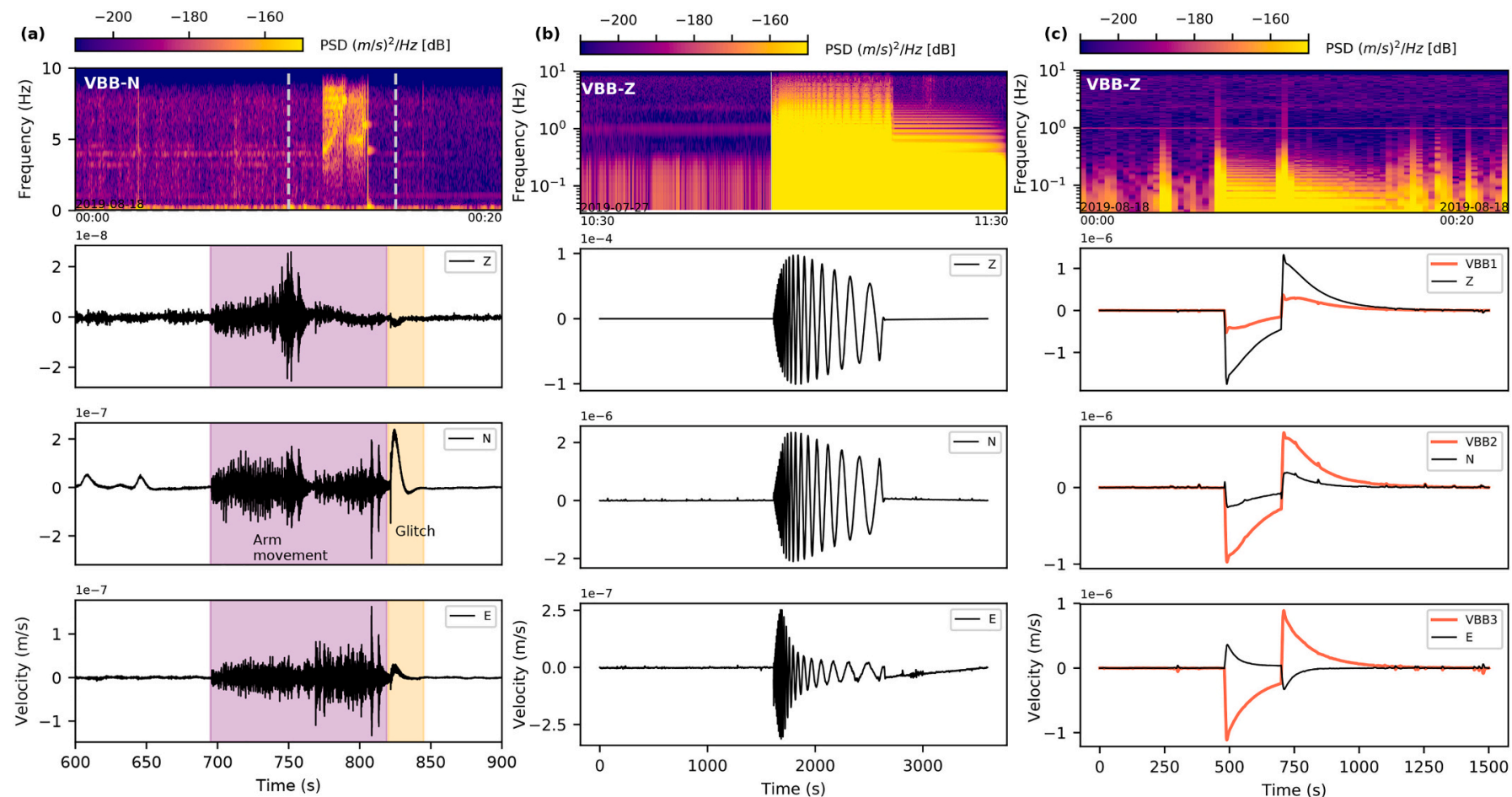

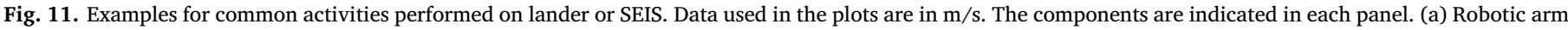

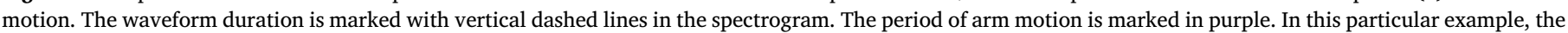

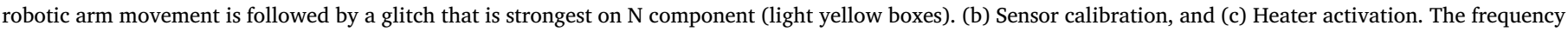

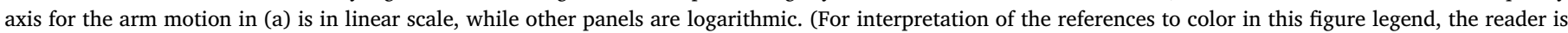
referred to the web version of this article.)

can be downloaded from doi:https://doi.org/10.5281/zenodo. 4065618.

\section{Acknowledgements}

We acknowledge NASA, CNES, their partner agencies and institutions (UKSA, SSO, DLR, JPL, IPGP-CNRS, ETHZ, IC, MPS-MPG) and the flight operations team at JPL, SISMOC, MSDS, IRIS-DMC and PDS for providing SEED SEIS data.

We also acknowledge the funding by (1) Swiss National Science Foundation and French Agence Nationale de la Recherche (SNF-ANR project "Seismology on Mars", ANR-14-CE36-0012-02 and MAGIS,
ANR-19-CE31-0008-08), (2) Swiss State Secretariat for Education, Research and Innovation (SEFRI project "MarsQuake ServicePreparatory Phase"), (3) ETH Research grant ETH-06 17-02 and, for French co-authors, (4) the French Space agency CNES. Additional support came from the Swiss National Supercomputing Centre (CSCS) under project ID s922. AH is funded by UKSA through grant \#ST/ R002096/1.

Visualizations were created using Matplotlib (Hunter, 2007). The data was processed with NumPy (Oliphant, 2006), Scipy (Jones et al., 2001), ObsPy (Krischer et al., 2015) and custom software developed by gempa GmbH.

This paper is InSight Contribution Number 150.

\section{Appendix A. List of acronyms and abbreviations}

\begin{tabular}{ll}
\hline APSS & Auxiliary Payload Sensor Suite \\
E-Box & Electronics Box \\
ENG & Engineering mode for seismometers \\
ERP & Event Request Proposal (to downlink data at high sampling rates) \\
HP & Heat flow and Physical Properties Package \\
InSight & Interior Exploration using Seismic Investigations, Geodesy and Heat Transport \\
LSA & Load Shunt Assembly \\
LSB & Least Significant Bit \\
LM & Lunar Module \\
LMST & Local Mean Solar Time \\
MAG & Magnetometer \\
MQS & Marsquake Service \\
SCI & Science mode for seismometers \\
SEED & Standard for the Exchange of Earthquake Data \\
SEIS & Seismic Experiment for Interior Structure package \\
SISMOC & SEIS on Mars Operations Center \\
SP & Short period seismometer \\
VBB & Very broadband seismometer \\
VEL & Velocity \\
WTS & Wind and Thermal Shield \\
\hline
\end{tabular}




\section{Appendix B. Supplementary data}

Supplementary data to this article can be found online at https://doi.org/10.1016/j.pepi.2020.106597.

\section{References}

Anderson, D.L., Miller, W., Latham, G., Nakamura, Y., Toksöz, M., Dainty, A., Duennebier, F., Lazarewicz, A.R., Kovach, R., Knight, T., 1977. Seismology on mars. J. Geophys. Res. 82, 4524-4546. https://doi.org/10.1029/JS082i028p04524.

Banerdt, W.B., Smrekar, S.E., Banfield, D., Giardini, D., Golombek, M., Johnson, C.L., Lognonné, P., Spiga, A., Spohn, T., Perrin, C., Stähler, S.C., Antonangeli, D., Asmar, S., Beghein, C., Bowles, N., Bozdag, E., Chi, P., Christensen, U., Clinton, J., Collins, G.S., Daubar, I., Dehant, V., Drilleau, M., Fillingim, M., Folkner, W., Garcia, R.F., Garvin, J., Grant, J., Grott, M., Grygorczuk, J., Hudson, T., Irving, J.C.E., Kargl, G., Kawamura, T., Kedar, S., King, S., Knapmeyer-Endrun, B., Knapmeyer, M., Lemmon, M., Lorenz, R., Maki, J.N., Margerin, L., McLennan, S.M., Michaut, C., Mimoun, D. Mittelholz, A., Mocquet, A., Morgan, P., Mueller, N.T., Murdoch, N., Nagihara, S., Newman, C., Nimmo, F., Panning, M., Pike, W.T., Plesa, A.C., Rodriguez, S. Rodriguez-Manfredi, J.A., Russell, C.T., Schmerr, N., Siegler, M., Stanley, S., Stutzmann, E., Teanby, N., Tromp, J., van Driel, M., Warner, N., Weber, R., Wieczorek, M., 2020. Initial results from the InSight mission on Mars. Nat. Geosci. 13, 183-189. https://doi.org/10.1038/s41561-020-0544-y.

Banfield, D., Rodriguez-Manfredi, J.A., Russell, C.T., Rowe, K.M., Leneman, D., Lai, H.R., Cruce, P.R., Means, J.D., Johnson, C.L., Mittelholz, A., Joy, S.P., Chi, P.J., Mikellides, I.G., Carpenter, S., Navarro, S., Sebastian, E., Gomez-Elvira, J., Torres, J., Mora, L., Peinado, V., Lepinette, A., Hurst, K., Lognonné, P., Smrekar, S.E., Banerdt, W.B., 2018. InSight auxiliary payload sensor suite (APSS). Space Sci. Rev. 215, 4. https:// doi.org/10.1007/s11214-018-0570-x.

Banfield, D., Spiga, A., Newman, C., Forget, F., Lemmon, M., Lorenz, R., Murdoch, N., Viudez-Moreiras, D., Pla-Garcia, J., Garcia, R.F., Lognonné, P., Karatekin, Ö., Perrin, C., Martire, L., Teanby, N., Hove, B.V., Maki, J.N., Kenda, B., Mueller, N.T., Rodriguez, S., Kawamura, T., McClean, J.B., Stott, A.E., Charalambous, C., Millour, E., Johnson, C.L., Mittelholz, A., Määttänen, A., Lewis, S.R., Clinton, J., Stähler, S.C., Ceylan, S., Giardini, D., Warren, T., Pike, W.T., Daubar, I., Golombek, M., Rolland, L., Widmer-Schnidrig, R., Mimoun, D., Beucler, É., Jacob, A., Lucas, A., Baker, M., Ansan, V., Hurst, K., Mora-Sotomayor, L., Navarro, S., Torres, J., Lepinette, A. Molina, A., Marin-Jimenez, M., Gomez-Elvira, J., Peinado, V., Rodriguez-Manfredi, J.A., Carcich, B.T., Sackett, S., Russell, C.T., Spohn, T., Smrekar, S.E., Banerdt, W.B., 2020. The atmosphere of Mars as observed by InSight. Nat. Geosci. 13, 190-198. https://doi.org/10.1038/s41561-020-0534-0.

Böse, M., Clinton, J.F., Ceylan, S., Euchner, F., van Driel, M., Khan, A., Giardini, D., Lognonné, P., Banerdt, W.B., 2017. A probabilistic framework for single-station location of seismicity on earth and Mars. Phys. Earth Planet. Int. 262, 48-65. https:// doi.org/10.1016/j.pepi.2016.11.003.

Böse, M., Giardini, D., Stähler, S., Ceylan, S., Clinton, J.F., van Driel, M., Khan, A., Euchner, F., Lognonné, P., Banerdt, W.B., 2018. Magnitude scales for marsquakes. Bull. Seismol. Soc. Am. 108, 2764-2777. https://doi.org/10.1785/0120180037.

Ceylan, S., van Driel, M., Euchner, F., Khan, A., Clinton, J., Krischer, L., Böse, M., Stähler, S., Giardini, D., 2017. From initial models of seismicity, structure and noise to synthetic seismograms for Mars. Space Sci. Rev. 211. https://doi.org/10.1007/s11214 017-0380-6.

Charalambous, C., Stott, A.E., Pike, W.T., McClean, J., Warren, T., Spiga, A., Banfield, D., Garcia, R.F., Clinton, J., Stähler, S.C., Navarro, S., Lognonne, P., Kawamura, T., Scholz, J.R., van Driel, M., Böse, M., Ceylan, S., Khan, A., Horleston, A., Mainsant, G., Sotomayor, L.M., Murdoch, N., Giardini, D., Banerdt, W.B., 2020. A comodulation analysis of atmospheric energy injection into the ground motion at InSight, Mars. Earth Space Sci. Open Arch. 48. https://doi.org/10.1002/essoar.10503206.1.

Clinton, J., Giardini, D., Lognonné, P., Banerdt, B., van Driel, M., Drilleau, M., Murdoch, N., Panning, M., Garcia, R., Mimoun, D., Golombek, M., Tromp, J., Weber, R., Böse, M., Ceylan, S., Daubar, I., Kenda, B., Khan, A., Perrin, L., Spiga, A., 2017. Preparing for InSight: an invitation to participate in a blind test for Martian seismicity. Seismol. Res. Lett. 88, 1290-1302. https://doi.org/10.1785/0220170094.

Clinton, J., Giardini, D., Böse, M., Ceylan, S., van Driel, M., Euchner, F., Garcia, R.F., Kedar, S., Khan, A., Stähler, S.C., Banerdt, B., Lognonne, P., Beucler, E., Daubar, I. Drilleau, M., Golombek, M., Kawamura, T., Knapmeyer, M., Knapmeyer-Endrun, B., Mimoun, D., Mocquet, A., Panning, M., Perrin, C., Teanby, N.A., 2018. The marsquake service: securing daily analysis of SEIS data and building the Martian seismicity catalogue for InSight. Space Sci. Rev. 214, 133. https://doi.org/10.1007/s11214 018-0567-5.

Clinton, J.F., Ceylan, S., Stähler, S., van Driel, M., Bose, M., Giardini, D., Charalambous, C., Dahmen, N.L., Horleston, A., Kawamura, T., Khan, A., Orhand-Mainsant, G., Scholz, J.R., Euchner, F., Banerdt, W.B., Lognonne, P., Banfield, D., Beucler, E., Garcia, R.F., Kedar, S., Panning, M.P., Pike, T., Smrekar, S.E., Spiga, A., 2020. Marsquake catalogue from InSight, Sols 0-478. Phys. Earth Planet. Int. 106595. https://doi.org/10.1016/j.pepi.2020.106595.

Dahmen, N.L., Clinton, J.F., Ceylan, S., van Driel, M., Giardini, D., Stähler, S., Böse, M., Charalambous, C., Horleston, A., Kawamura, T., Khan, A., Orhand-Mainsant, G., Scholz, J., Euchner, F., Pike, William T., Weber, R.C., Lognonné, P., Banerdt, W.B., 2020. Super high frequency events: a new class of events recorded by the InSight seismometers on Mars (submitted). J. Geophys. Res., e2020JE006599. https://doi. org/10.1029/2020JE006599.

van Driel, M., Ceylan, S., Clinton, J.F., Giardini, D., Alemany, H., Allam, A., Ambrois, D.,
Balestra, J., Banerdt, B., Becker, D., Böse, M., Boxberg, M.M.S., Brinkman, N., Casademont, T., Chèze, J., Daubar, I., Deschamps, A., Dethof, F., Ditz, M., Drilleau, M., Essing, D., Euchner, F., Fernando, B., Garcia, R., Garth, T., Godwin, H., Golombek, M.M.P., Grunert, K., Hadziioannou, C., Haindl, C., Hammer, C., Hochfeld, I., Hosseini, K., Hu, H., Kedar, S., Kenda, B., Khan, A., Kilchling, T., KnapmeyerEndrun, B., Lamert, A., Li, J., Lognonné, P., Mader, S., Marten, L., Mehrkens, F. Mercerat, D., Mimoun, D., Möller, T., Murdoch, N., Neumann, P., Neurath, R., Paffrath, M., Panning, M.M.P., Peix, F., Perrin, L., Rolland, L., Schimmel, M., Schröer, C., Spiga, A., Stähler, S.C.S., Steinmann, R., Stutzmann, E., Szenicer, A., Trumpik, N., Tsekhmistrenko, M., Twardzik, C., Weber, R., Werdenbach-Jarklowski, P., Zhang, S., Zheng, Y., 2019. Preparing for InSight: evaluation of the blind test for martian seismicity. Seismol. Res. Lett. 90. https://doi.org/10.1785/0220180379.

van Driel, M., Ceylan, S., Clinton, J.F., Giardini, D., Horleston, A., Margerin, L., Stähler, S., Böse, M., Charalambous, C., Kawamura, T., Khan, A., Orhand-Mainsant, G. Scholz, J., Euchner, F., Knapmeyer, M., Pike, W., Lognonné, P., Banerdt, W., 2020. High frequency seismic events on Mars observed by InSight. JGR Planets (submitted).

Garcia, R.F., Kenda, B., Kawamura, T., Spiga, A., Murdoch, N., Lognonné, P., WidmerSchnidrig, R., Compaire, N., Orhand-Mainsant, G., Banfield, D., Banerdt, W.B., 2020 Pressure effects on the SEIS-InSight instrument, improvement of seismic records and characterization of long period atmospheric waves from ground displacements. J. Geophys. Res. 125. https://doi.org/10.1029/2019je006278.

Giardini, D., Lognonné, P., Banerdt, W.B., Pike, W.T., Christensen, U., Ceylan, S., Clinton, J.F., van Driel, M., Stähler, S., Böse, M., Garcia, R.F., Khan, A., Panning, M., Perrin, C., Banfield, D., Beucler, E., Charalambous, C., Euchner, F., Horleston, A., Jacob, A., Kawamura, T., Kedar, S., Orhand-Mainsant, G., Scholz, J.R., Smrekar, S., Spiga, A., Agard, C., Antonangeli, D., Barkaoui, S., Barrett, E., Combes, P., Conejero, V., Daubar, I., Drilleau, M., Ferrier, C., Gabsi, T., Gudkova, T., Hurst, K., Karakostas, F., King, S., Knapmeyer, M., Knapmeyer-Endrun, B., Llorca-Cejudo, R., Lucas, A., Luno, L.,

Margerin, L., McClean, J., Mimoun, D., Murdoch, N., Nimmo, F., Nonon, M., Pardo, C., Rivoldini, A., Rodriguez Manfredi, J.A., Samuel, H., Schimmel, M., Stott, A.E., Stutzman, E., Teanby, N., Warren, T., Weber, R., Wieczorek, M., Yana, C., 2020. The seismicity of Mars. Nat. Geosci. https://doi.org/10.1038/s41561-020-0539-8.

Hunter, J.D., 2007. Matplotlib: a 2D graphics environment. Comput. Sci. Eng. 9, 90-95. https://doi.org/10.1109/MCSE.2007.55.

Hurst, K., Fayon, L., Knapmeyer-Endrun, B., Schmelzbach, C., van Driel, M., Ervin, J., Kedar, S., Pike, W., Bierwirth, M., Lognonne, P., Ceylan, S., Bose, M., Clinton, J. Giardini, D., Horleston, A., Kawamura, T., Khan, A., Orhand-Mainsant, G., Scholz, J., Stahler, S., Stevanovic, J., Banerdt, W., 2020. Resonances of the InSight seismometer on Mars. J. Geophys. Res (to be submitted).

InSight Mars SEIS Data Service, 2019a. SEIS Raw Data, Insight Mission. IPGP, JPL, CNES, ETHZ, ICL, MPS, ISAE-Supaero, LPG, MFSC. https://doi.org/10.18715/SEIS. INSIGHT.XB.

InSight Mars SEIS Data Service, 2019b. InSight SEIS Data Bundle. PDS Geosciences (GEO) Node. https://doi.org/10.17189/1517570.

InSight Marsquake Service, 2020. Mars Seismic Catalogue, InSight Mission; V3 2020-0701. ETHZ, IPGP, JPL, ICL, ISAE-Supaero, MPS. Univ Bristolhttps://doi.org/10. 12686/a8. (Dataset)

IRIS, 2012. Standard for the Exchange of Earthquake Data (SEED) Manual. URL. http: WWw fdsn org/pdf/SF,DManual, V2,4 pof.

Johnson, C.L., Mittelholz, A., Langlais, B., Russell, C.T., Ansan, V., Banfield, D., Chi, P.J., Fillingim, M.O., Forget, F., Haviland, H.F., Golombek, M., Joy, S., Lognonné, P., Liu, X., Michaut, C., Pan, L., Quantin-Nataf, C., Spiga, A., Stanley, S., Thorne, S.N., Wieczorek, M.A., Yu, Y., Smrekar, S.E., Banerdt, W.B., 2020. Crustal and time-varying magnetic fields at the InSight landing site on Mars. Nat. Geosci. 13, 199-204. https:// doi.org/10.1038/s41561-020-0537-x.

Jones, E., Oliphant, T., Peterson, P., Others, 2001. SciPy: Open Source Scientific Tools for Python. http://www.scipy.org/.

Kenda, B., Drilleau, M., Garcia, R., Kawamura, T., Murdoch, N., Compaire, N., Lognonne, P., Spiga, A., Widmer-Schnidrig, R., 2020. Subsurface structure at the InSight landing site from compliance measurements by seismic and meteorological experiments. J. Geophys. Res (submitted).

Khan, A., van Driel, M., Böse, M., Giardini, D., Ceylan, S., Yan, J., Clinton, J., Euchner, F., Lognonné, P., Murdoch, N., Mimoun, D., Panning, M., Knapmeyer, M., Banerdt, W.B., 2016. Single-station and single-event marsquake location and inversion for structure using synthetic Martian waveforms. Phys. Earth Planet. Int. 258, 28-42. https://doi. org/10.1016/j.pepi.2016.05.017.

Krischer, L., Megies, T., Barsch, R., Beyreuther, M., Lecocq, T., Caudron, C., Wassermann, J., 2015. ObsPy: a bridge for seismology into the scientific Python ecosystem. Comput. Sci. Discov. 8, 014003. https://doi.org/10.1088/1749-4699/8/1/014003.

Latham, G.V., Ewing, M., Press, F., Sutton, G., Dorman, J., Nakamura, Y., Toksoz, N., Duennebier, F., Lammlein, D., 1971. Passive seismic experiment. NASA Spec. Publ. 272, 133-161.

Lognonné, P., Banerdt, W.B., Giardini, D., Pike, W., Christensen, U., Laudet, P., de Raucourt, S., Zweifel, P., Calcutt, S., Bierwirth, M., Hurst, K., Ijpelaan, F., Umland, J., Llorca-Cejudo, R., Larson, S., Garcia, R., Kedar, S., Knapmeyer-Endrun, B., Mimoun, D., Mocquet, A., Panning, M., Weber, R., Sylvestre-Baron, A., Pont, G., Verdier, N., Kerjean, L., Facto, L., Gharakanian, V., Feldman, J., Hoffman, T., Klein, D.B., Klein, K., Onufer, N., Paredes-Garcia, J., Petkov, M., Willis, J., Smrekar, S., Drilleau, M., Gabsi, T., Nebut, T., Robert, O., Tillier, S., Moreau, C., Parise, M., Aveni, G., Ben 
Charef, S., Bennour, Y., Camus, T., Dandonneau, P., Desfoux, C., Lecomte, B., Pot, O., Revuz, P., Mance, D., ten Pierick, J., Bowles, N., Charalambous, C., Delahunty, A., Hurley, J., Irshad, R., Liu, H., Mukherjee, A., Standley, I., Stott, A., Temple, J., Warren, T., Eberhardt, M., Kramer, A., Kühne, W., Miettinen, E.P., Monecke, M., Aicardi, C., André, M., Baroukh, J., Borrien, A., Bouisset, A., Boutte, P., Brethomé, K., Brysbaert, C., Carlier, T., Deleuze, M., Desmarres, J.M., Dilhan, D., Doucet, C., Faye, D., Faye-Refalo, N., Gonzalez, R., Imbert, C., Larigauderie, C., Locatelli, E., Luno, L., Meyer, J.R., Mialhe, F., Mouret, J.M., Nonon, M., Pahn, Y., Paillet, A., Pasquier, P., Perez, G., Perez, R., Perrin, L., Pouilloux, B., Rosak, A., Savin de Larclause, I., Sicre, J., Sodki, M., Toulemont, N., Vella, B., Yana, C., Alibay, F., Avalos, O., Balzer, M., Bhandari, P., Blanco, E., Bone, B., Bousman, J., Bruneau, P., Calef, F., Calvet, R., D'Agostino, S., de los Santos, G., Deen, R., Denise, R., Ervin, J., Ferraro, N., Gengl, H., Grinblat, F., Hernandez, D., Hetzel, M., Johnson, M.E., Khachikyan, L., Lin, J., Madzunkov, S., Marshall, S., Mikellides, I., Miller, E., Raff, W., Singer, J., Sunday, C., Villalvazo, J., Wallace, M., Banfield, D., Rodriguez-Manfredi, J., Russell, C., TrebiOllennu, A., Maki, J., Beucler, E., Böse, M., Bonjour, C., Berenguer, J., Ceylan, S. Clinton, J., Conejero, V., Daubar, I., Dehant, V., Delage, P., Euchner, F., Estève, I., Fayon, L., Ferraioli, L., Johnson, C.L., Gagnepain-Beyneix, J., Golombek, M., Khan, A., Kawamura, T., Kenda, B., Labrot, P., Murdoch, N., Pardo, C., Perrin, C., Pou, L. Sauron, A., Savoie, D., Stähler, S., Stutzmann, E., Teanby, N., Tromp, J., van Driel, M., Wieczorek, M., Widmer-Schnidrig, R., Wookey, J., 2019. SEIS: Insight's seismic experiment for internal structure of Mars. Space Sci. Rev. 215, 12. https://doi.org/ 10.1007/s11214-018-0574-6.

Lognonné, P., Banerdt, W., Pike, W., Giardini, D., Christensen, U., Garcia, R., Kawamura, T., Kedar, S., Knapmeyer-Endrun, B., Margerin, L., Nimmo, F., Panning, M., Tauzin, B., Scholz, J.R., Antonangeli, D., Barkaoui, S., Beucler, E., Bissig, F., Brinkman, N., Calvet, M., Ceylan, S., Charalambous, C., Davis, P., van Driel, M., Drilleau, M., Fayon, L., Joshi, R., Kenda, B., Khan, A., Knapmeyer, M., Lekic, V., McClean, J., Mimoun, D., Murdoch, N., Pan, L., Perrin, C., Pinot, B., Pou, L., Menina, S., Rodriguez, S., Schmelzbach, C., Schmerr, N., Sollberger, D., Spiga, A., Stähler, S., Stott, A., Stutzmann, E., Tharimena, S., Widmer-Schnidrig, R., Andersson, F., Ansan, V., Beghein, C., Böse, M., Bozdag, E., Clinton, J., Daubar, I., Delage, P., Fuji, N., Golombek, M., Grott, M., Horleston, A., Hurst, K., Irving, J., Jacob, A., Knollenberg, J., Krasner, S., Krause, C., Lorenz, R., Michaut, C., Myhill, B., Nissen-Meyer, T., ten Pierick, J., Plesa, A.C., Quantin-Nataf, C., Robertsson, J., Rochas, L., Schimmel, M., Smrekar, S., Spohn, T., Teanby, N., Tromp, J., Vallade, J., Verdier, N., Vrettos, C., Weber, R., Banfield, D., Barrett, E., Bierwirth, E., Calcutt, S., Compaire, N., Johnson, C., Mance, D., Euchner, F., Kerjean, L., Mainsant, G., Mocquet, A., Antonio Rodriguez Manfredi, J., Pont, G., Laudet, P., Nebut, T., de Raucourt, S., Robert, O., Russell, C., Sylvestre-Baron, A., Tillier, S., Warren, T., Wieczorek, M., Yana, C., Zweifel, P., 2020. Constraints on the shallow elastic and anelastic structure of Mars from InSight seismic data. Nat. Geosci. https://doi.org/10.1038/s41561-020-0536-y.

Lorenz, R.D., Kedar, S., Murdoch, N., Lognonné, P., Kawamura, T., Mimoun, D., Bruce Banerdt, W., 2015. Seismometer detection of dust devil vortices by ground tilt. Bull. Seismol. Soc. Am. 105, 3015-3023. https://doi.org/10.1785/0120150133.

Lorenz, R.D., Nakamura, Y., Murphy, J.R., 2017. Viking-2 seismometer measurements on
Mars: PDS data archive and meteorological applications. Earth Space Sci. 4, 681-688. https://doi.org/10.1002/2017EA000306.

Murdoch, N., Mimoun, D., Garcia, R.F., Rapin, W., Kawamura, T., Lognonné, P., Banfield, D., Banerdt, W.B., 2017. Evaluating the Wind-Induced Mechanical Noise on the InSight Seismometers. https://doi.org/10.1007/s11214-016-0311-y.

Murdoch, N., Alazard, D., Knapmeyer-Endrun, B., Teanby, N.A., Myhill, R., 2018. Flexible Mode Modelling of the InSight Lander and Consequences for the SEIS Instrument. https://doi.org/10.1007/s11214-018-0553-y.

Oliphant, T.E., 2006. Guide to NumPy. http://www.trelgol.com.

Panning, M.P., Beucler, E., Drilleau, M., Mocquet, A., Lognonné, P., Banerdt, W.B., 2015. Verifying single-station seismic approaches using earth-based data: preparation for data return from the InSight mission to Mars. Icarus 248, 230-242. https://doi.org/ 10.1016/j.icarus.2014.10.035.

Panning, M.P., Pike, W.T., Lognonné, P., Banerdt, W.B., Murdoch, N., Banfield, D., Charalambous, C., Kedar, S., Lorenz, R.D., Marusiak, A.G., McClean, J.B., Nunn, C., Stähler, S.C., Stott, A.E., Warren, T., 2020. On-deck seismology: lessons from InSight for future planetary seismology. J. Geophys. Res. 125. https://doi.org/10.1029/ 2019JE006353.

Savoie, D., Richard, A., Goutaudier, M., Lognonné, P.H., Hurst, K., Maki, J.N., Golombek, M.P., van Driel, M., Clinton, J., Stutzmann, E., et al., 2020. Finding SEIS North on Mars: comparisons between SEIS sundial, Inertial and Imaging measurements and consequences for seismic analysis. Earth Space Sci. Open Arch. https://doi.org/10 1002/essoar.10503306.1.

Scholz, J.R., Widmer-Schnidrig, R., Davis, P., Lognonné, P., Pinot, B., Garcia, R.F., Hurst, K., Pou, L., Nimmo, F., Barkaoui, S., et al., 2020. Detection, analysis and removal of glitches from insight's seismic data from mars. Earth Space Sci. Open Arch. 7, e2020EA001317. https://doi.org/10.1029/2020EA001317.

Spiga, A., Murdoch, N., Lorenz, R., Forget, F., Newman, C., Rodriguez, S., Pla-Garcia, J., Moreiras, D.V., Banfield, D., Perrin, C., Mueller, N.T., Millour, E., Banerdt, W., 2020 A study of daytime convective vortices and turbulence in the martian Planetary Boundary Layer based on half-a-year of InSight atmospheric measurements and Large-Eddy Simulations. J. Geophys. Res. arXiv:2005.01134 (submitted).

Spohn, T., Grott, M., Smrekar, S.E., Knollenberg, J., Hudson, T.L., Krause, C., Müller, N., Jänchen, J., Börner, A., Wippermann, T., Krömer, O., Lichtenheldt, R., Wisniewski, L., Grygorczuk, J., Fittock, M., Rheershemius, S., Spröwitz, T., Kopp, E., Walter, I., Plesa, A.C., Breuer, D., Morgan, P., Banerdt, W.B., 2018. The heat flow and physical properties package (HP3) for the InSight mission. Space Sci. Rev. 214. https://doi. org/10.1007/s11214-018-0531-4.

Stott, A.E., Charalambous, C., Warren, T.J., Pike, W.T., 2018. Full-band signal extraction from sensors in extreme environments: the NASA InSight microseismometer. IEEE Sensors J. https://doi.org/10.1109/JSEN.2018.2871342.

Stutzmann, E., Schimmel, M., Lognonné, P.H., Horleston, A.C., Ceylan, S., van Driel, M., Stähler, S.C., Banerdt, W.B., Calvet, M., Charalambous, C., et al., 2020. Polarized ambient noise on mars. Earth Space Sci. Open Arch. 41. https://doi.org/10.1002/ essoar.10503376.1. 